\title{
Artificial Light-Harvesting Metallacycle System with Sequential Energy Transfer for Photochemical Catalysis
}

Dengqing Zhang, ${ }^{*}, \dagger$ Wei Yu,${ }^{\dagger}$ Suwan $\mathrm{Li},{ }^{\dagger}$ Yan Xia,${ }^{\dagger}$ Xianying $\mathrm{Li},{ }^{\ddagger}$ Yiran $\mathrm{Li},{ }^{\S}$ and Tao $\mathrm{Yi}^{*}, \dagger$

${ }^{\dagger}$ State Key Laboratory for Modification of Chemical Fibers and Polymer Materials, College of Chemistry, Chemical Engineering and Biotechnology, Donghua University, Shanghai, 201620, China

$\$$ School of Environmental Science and Engineering, Donghua University, Shanghai, 201620, China

$\S$ Department of Chemistry, Fudan University, Shanghai 200433, China 


\section{Table of contents}

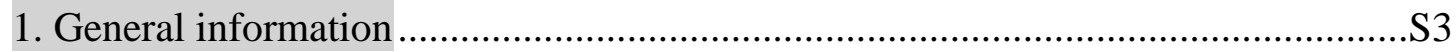

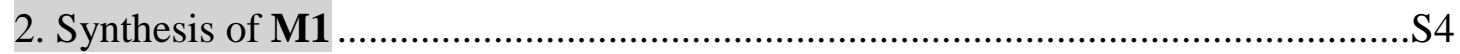

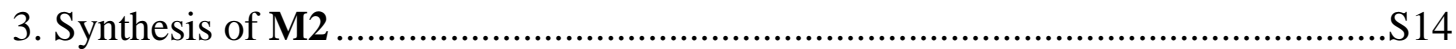

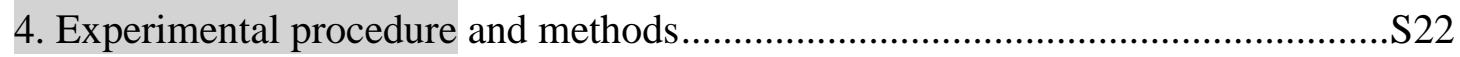

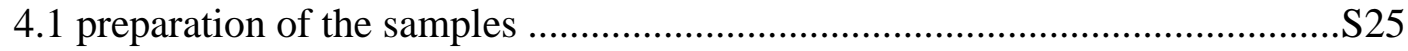

4.2 Energy transfer efficiency $\left(\Phi_{\mathrm{ET}}\right)$ calculation .. SError! Bookmark not defined.

4.3 Antenna effect (AE) calculation …...............SError! Bookmark not defined.

4.4 M1-ESY-SR101 system for the photocatalytic reaction in aqueous medium SError! Bookmark not defined.

5. Additional tables SError! Bookmark not defined.

6. Additional spectra and images SError! Bookmark not defined.

7. References $\mathrm{S} 40$ 


\section{General information}

All reagents and deuterated solvents were commercially available and used without further purification. Compound 4,4'-(2,2-diphenylethene-1,1-diyl) bis(bromobenzene $)^{[1]} 、 \mathbf{4}^{[2]}$ and $\mathbf{9}^{[3]}$ were prepared according to the published

procedure. ${ }^{1} \mathrm{H}$ NMR and ${ }^{13} \mathrm{C}$ NMR spectra were recorded in $\mathrm{CDCl}_{3}$ or $\mathrm{CD}_{2} \mathrm{Cl}_{2}$ on Bruker Model Avance DMX 400 (400 MHz) at room temperature. Absorption spectra were recorded on a PERSEE model TU-1901 spectrophotometer. Fluorescence spectra were recorded on a F-7000 FL Spectrophotometer. The fluorescence lifetimes were measured employing time correlated single photon counting on a FLS1000 instrument. The quantum yields have been measured on a PTI QM 40 instrument with the integrating sphere. Transmission electron microscopy (TEM) investigations were carried out on a JEOL JEM-2100 instrument. Scanning electron microscopy (SEM) images were recorded with a Hitachi S-4800 or SU8010 instruments. Dynamic light scattering (DLS) measurements were performed at a Malvern Instrument. Zeta-potential measurements were performed at $25{ }^{\circ} \mathrm{C}$ on a Zetasizer Nano $\mathrm{Z}$ apparatus. Matrix-assisted laser desorption-ionization time-of-flight mass spectrometry (MALDI-TOF mass) was recorded on 4800 Module Diagnostics from ABSCIEX. ESI-TOF-mass spectrum was recorded on a Micromass Quattro II triple-quadrupole mass spectrometer using electrospray ionization with a MassLynx operating system. 


\section{Synthesis of M1}

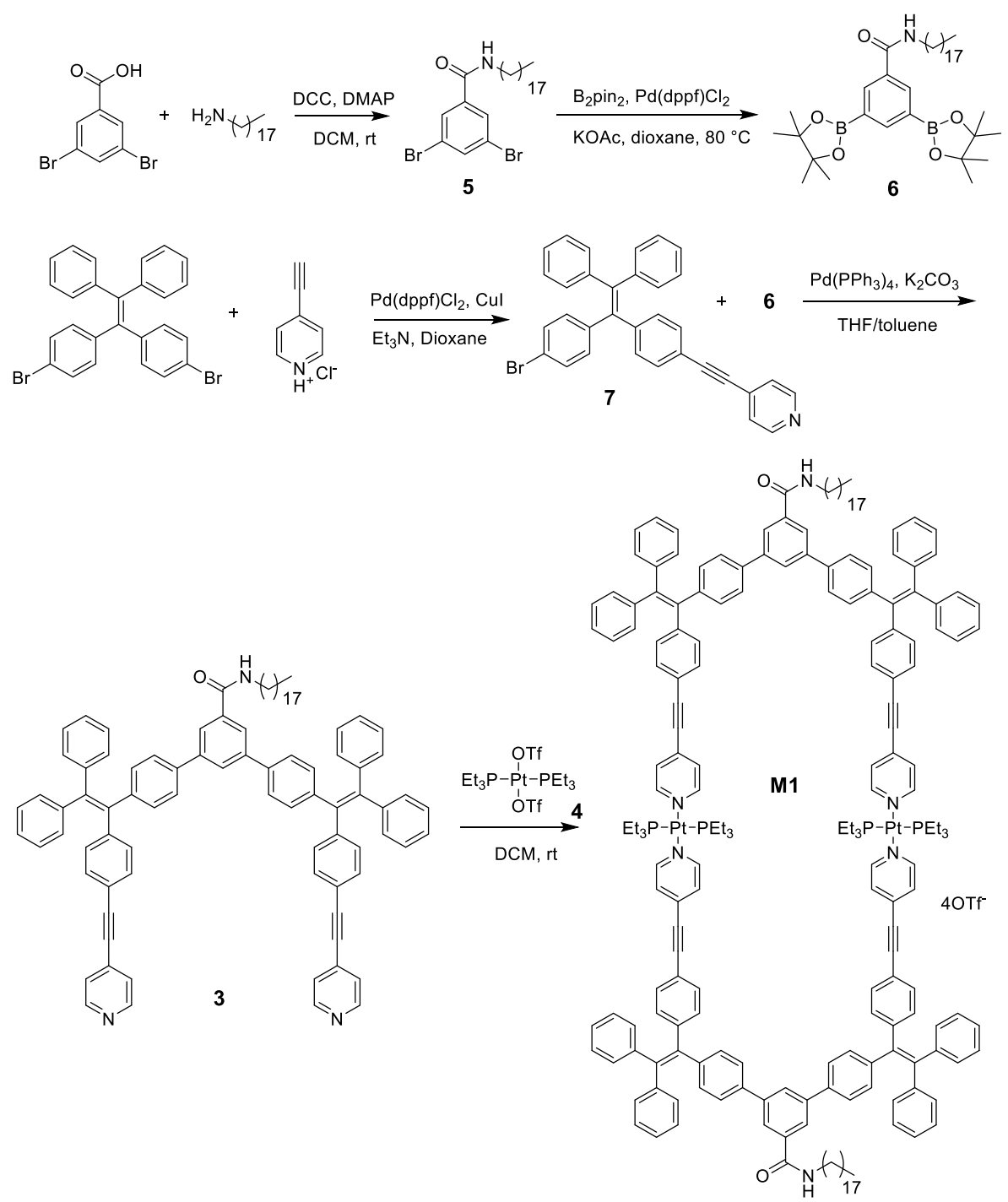

Figure S1. Synthesis route of M1.

Synthesis of 5

To a solution of 3,5-dibromobenzoic acid (2.8 g, $5.36 \mathrm{mmol})$, octadecan-1-amine $(1.73 \mathrm{~g}, 6.43 \mathrm{mmol})$ in anhydrous dichloromethane $(40 \mathrm{~mL})$ was added of 4-dimethylaminopyridine (DMAP) $\quad(980 \quad \mathrm{mg}, \quad 8.04 \quad \mathrm{mmol})$. Then $N, N$-dicyclohexylcarbodiimide (DCC) $(1.65 \mathrm{~g}, 8.04 \mathrm{mmol})$ in $20 \mathrm{~mL}$ anhydrous dichloromethane was added to the reaction mixture, followed by stirring for $24 \mathrm{~h}$ at room temperature. The precipitated urea was filtered off. The filtrate was subsequently evaporated under vacuo. The residue was purified by column 
chromatography on silica gel $\left(\mathrm{CH}_{2} \mathrm{Cl}_{2} /\right.$ petroleum ether $\left.=1 / 1\right)$ to give compound $\mathbf{5}$ as a white solid. Yeild: $1.70 \mathrm{~g}, 60 \% .{ }^{1} \mathrm{H}$ NMR $\left(400 \mathrm{MHz}, \mathrm{CDCl}_{3}, 298 \mathrm{~K}\right) \delta(\mathrm{ppm})=7.81(\mathrm{~s}$, 2H), $7.78(\mathrm{~s}, 1 \mathrm{H}), 6.08(\mathrm{~s}, 1 \mathrm{H}), 3.43(\mathrm{q}, J=6.68 \mathrm{~Hz}, 2 \mathrm{H}), 1.64-1.57(\mathrm{~m}, 2 \mathrm{H})$, 1.33-1.25 (m, 30H), $0.88(\mathrm{t}, J=6.28 \mathrm{~Hz}, 3 \mathrm{H}) .{ }^{13} \mathrm{C} \mathrm{NMR}\left(101 \mathrm{MHz}, \mathrm{CDCl}_{3}\right) \delta 164.68$, $138.17,136.69,128.86,123.27,40.43,31.94,29.71,29.69,29.67,29.66,29.60,29.56$, 29.53, 29.38, 29.30, 26.97, 22.71, 14.14. ESI-MS: $\mathrm{m} / \mathrm{z}$ Calcd for $\mathrm{C}_{25} \mathrm{H}_{41} \mathrm{Br}_{2} \mathrm{NO}$ $[\mathrm{M}+\mathrm{H}]^{+}$532.2, found 532.2.

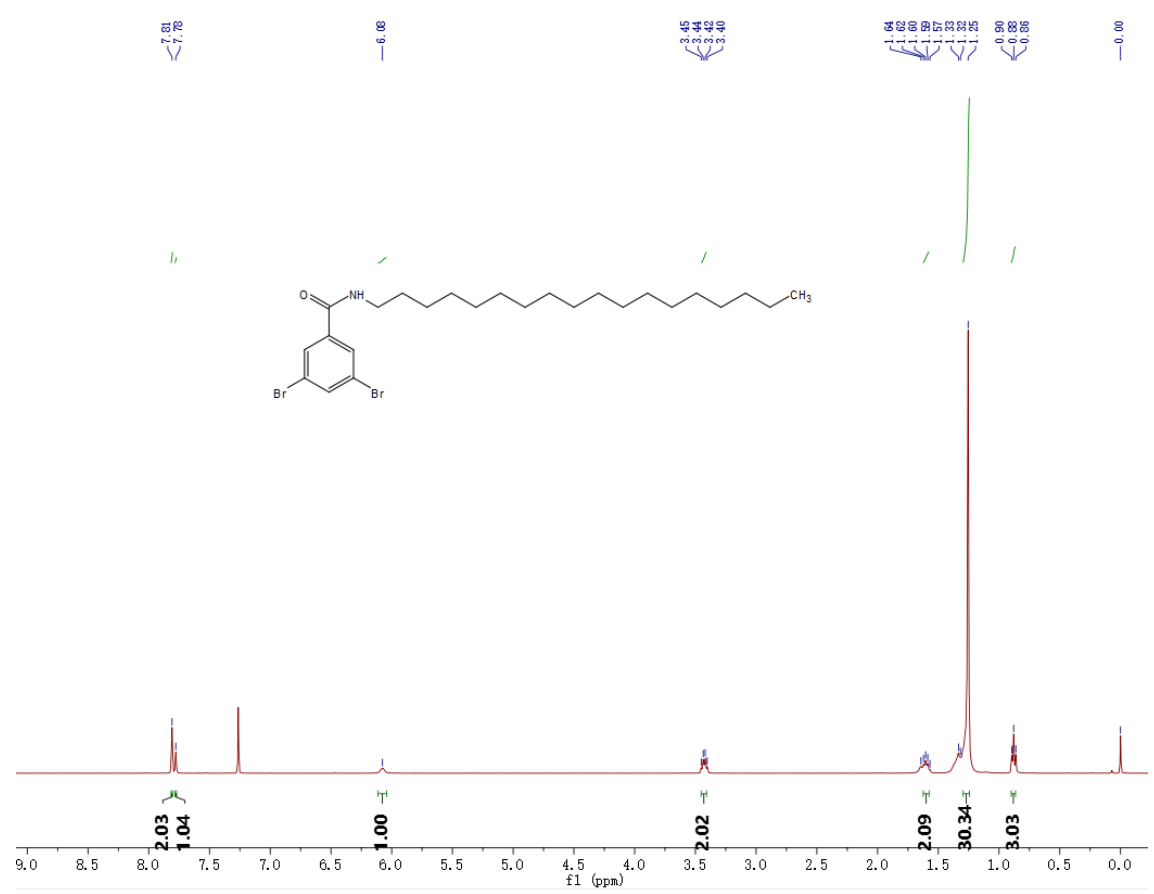

Figure S2. ${ }^{1} \mathrm{H}$ NMR spectrum $\left(400 \mathrm{MHz}, \mathrm{CDCl}_{3}, 298 \mathrm{~K}\right)$ of compound $\mathbf{5}$. 


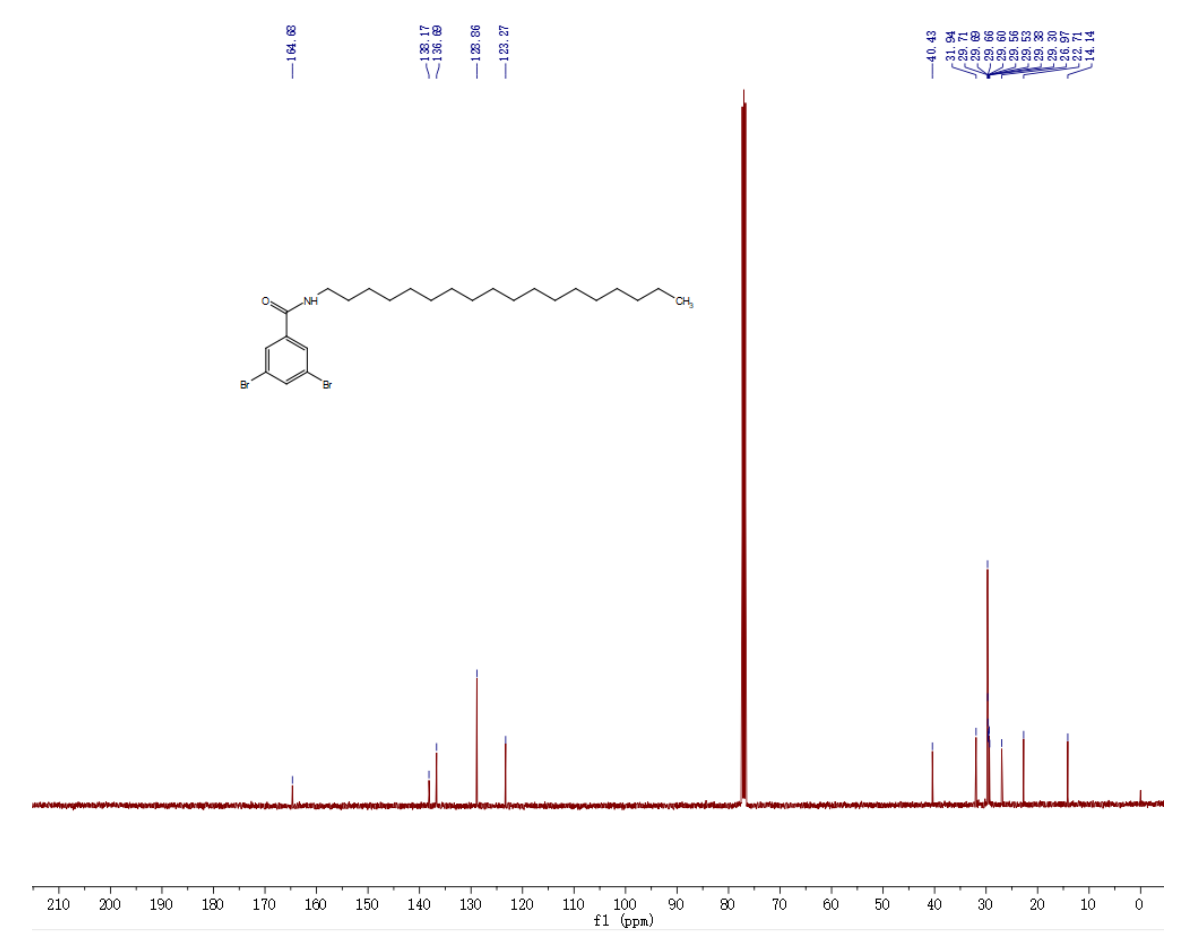

Figure S3. ${ }^{13} \mathrm{C}$ NMR spectrum $\left(101 \mathrm{MHz}, \mathrm{CDCl}_{3}, 298 \mathrm{~K}\right)$ of compound $\mathbf{5}$.

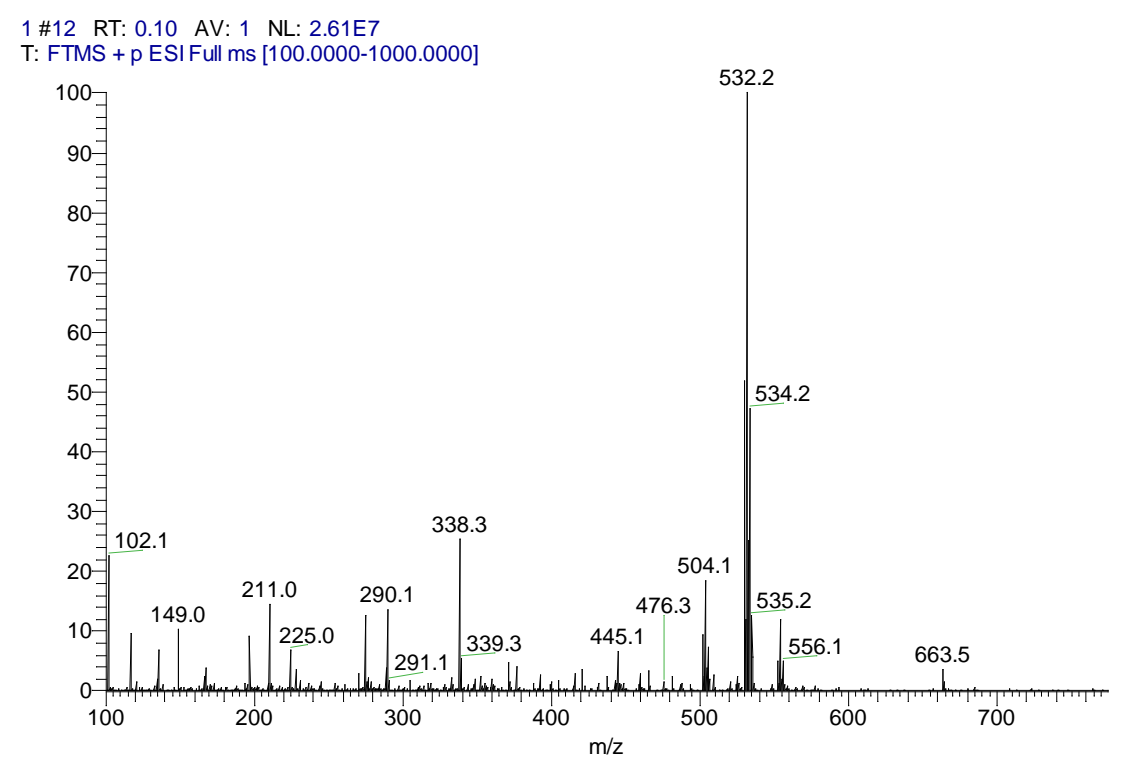

Figure S4. ESI spectrum of compound 5.

Synthesis of 6

A Schlenk tube was charged with 5 (800 mg, $1.51 \mathrm{mmol})$, bis(pinacolato)diboron (953 mg, $3.77 \mathrm{mmol}), \mathrm{Pd}(\mathrm{dppf}) \mathrm{Cl}_{2}(56.8 \mathrm{mg}, 0.08 \mathrm{mmol})$, and potassium acetate (1.03 $\mathrm{g}, 10.57 \mathrm{mmol})$ in anhydrous 1,4 -dioxane $(20 \mathrm{~mL})$. The reaction was performed at $80{ }^{\circ} \mathrm{C}$ for $3 \mathrm{~h}$ under nitrogen. The solvent was removed and the residue was purified by 
column chromatography on silica gel (ethyl acetate/petroleum ether) $=1 / 5$ ) to afford compound 6 as yellow oil. Yield: $528 \mathrm{mg}, 56 \% .{ }^{1} \mathrm{H} \mathrm{NMR}\left(400 \mathrm{MHz}, \mathrm{CDCl}_{3}, 298 \mathrm{~K}\right) \delta$ $(\mathrm{ppm})=8.37(\mathrm{~s}, 1 \mathrm{H}), 8.27(\mathrm{~d}, J=1.04 \mathrm{~Hz}, 2 \mathrm{H}), 6.22(\mathrm{t}, J=5.4 \mathrm{~Hz}, 1 \mathrm{H}), 3.43(\mathrm{dd}, J=$ $13.286 .8 \mathrm{~Hz}, 2 \mathrm{H}), 1.64-1.59(\mathrm{~m}, 2 \mathrm{H}), 1.34(\mathrm{~s}, 24 \mathrm{H}), 1.30-1.24(\mathrm{~m}, 30 \mathrm{H}), 0.88$ (t, $J=$ $6.64 \mathrm{~Hz}, 3 \mathrm{H}) .{ }^{13} \mathrm{C} \mathrm{NMR}\left(101 \mathrm{MHz}, \mathrm{CDCl}_{3}, 298 \mathrm{~K}\right) \delta 167.31,140.18,136.37,134.77$, $131.35,129.37,84.27,84.06,40.28,31.95,29.77,29.72,29.68,29.65,29.59,29.39$, 27.08, 24.91, 22.71, 14.15. ESI-MS: m/z Calcd for $\mathrm{C}_{37} \mathrm{H}_{65} \mathrm{~B}_{2} \mathrm{NO}_{5}[\mathrm{M}+\mathrm{H}]^{+} 626.5$, found 626.5 .

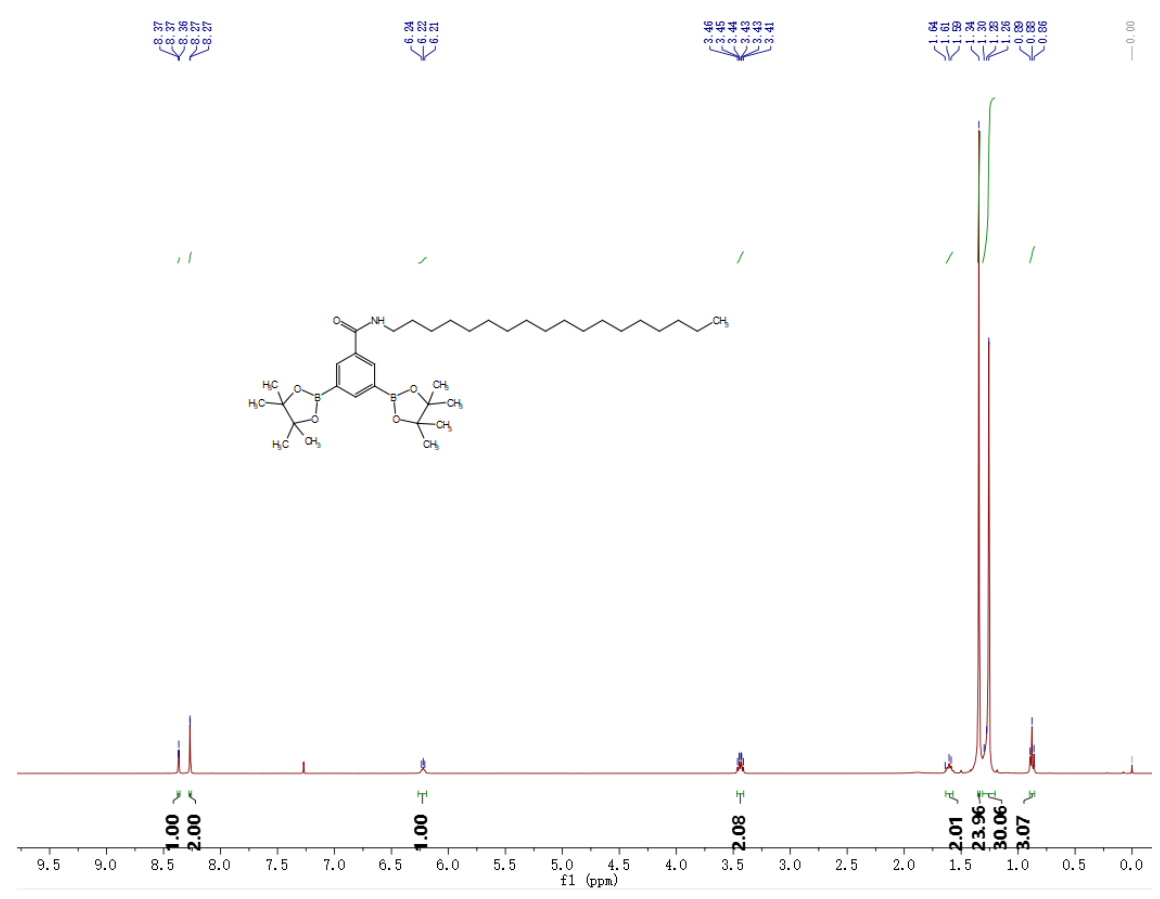

Figure S5. ${ }^{1} \mathrm{H}$ NMR spectrum (400 $\left.\mathrm{MHz}, \mathrm{CDCl}_{3}, 298 \mathrm{~K}\right)$ of compound 6. 

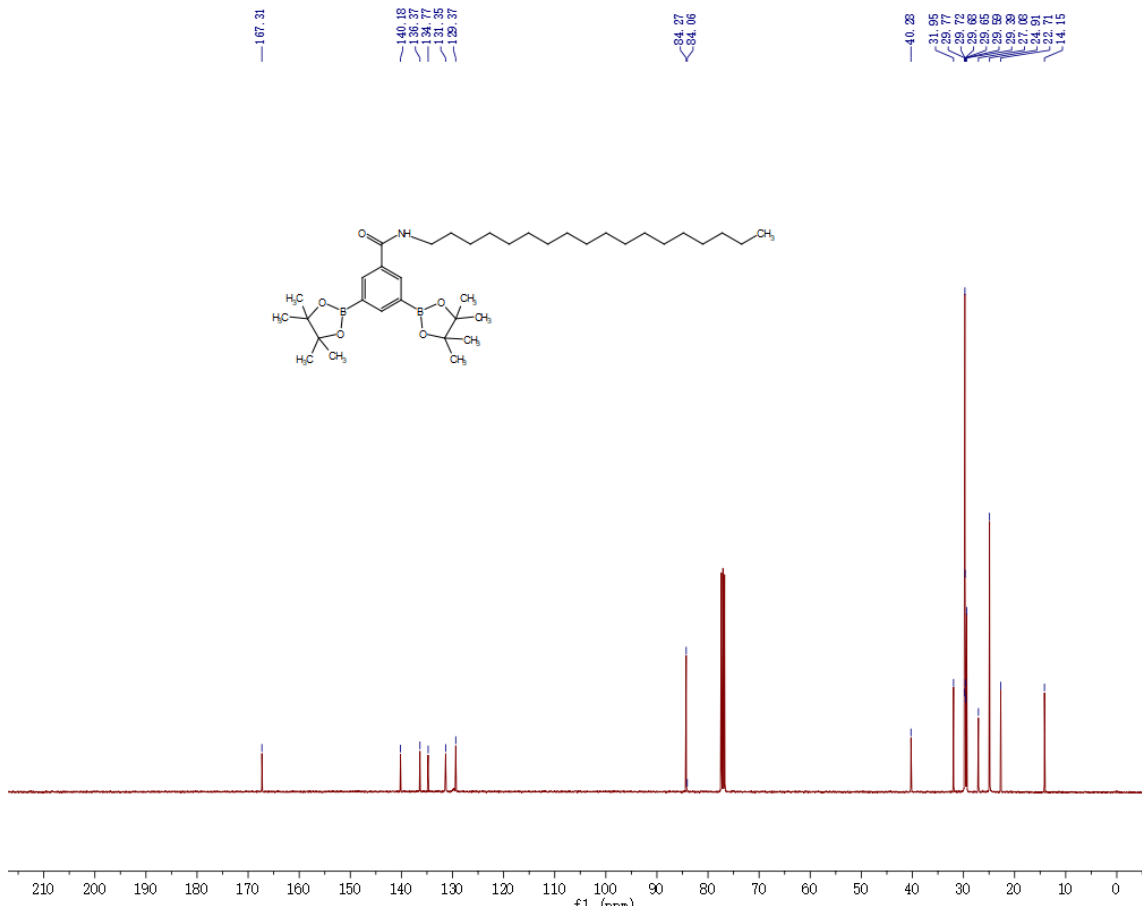

Figure S6. ${ }^{13} \mathrm{C}$ NMR spectrum $\left(101 \mathrm{MHz}, \mathrm{CDCl}_{3}, 298 \mathrm{~K}\right)$ of compound 6.

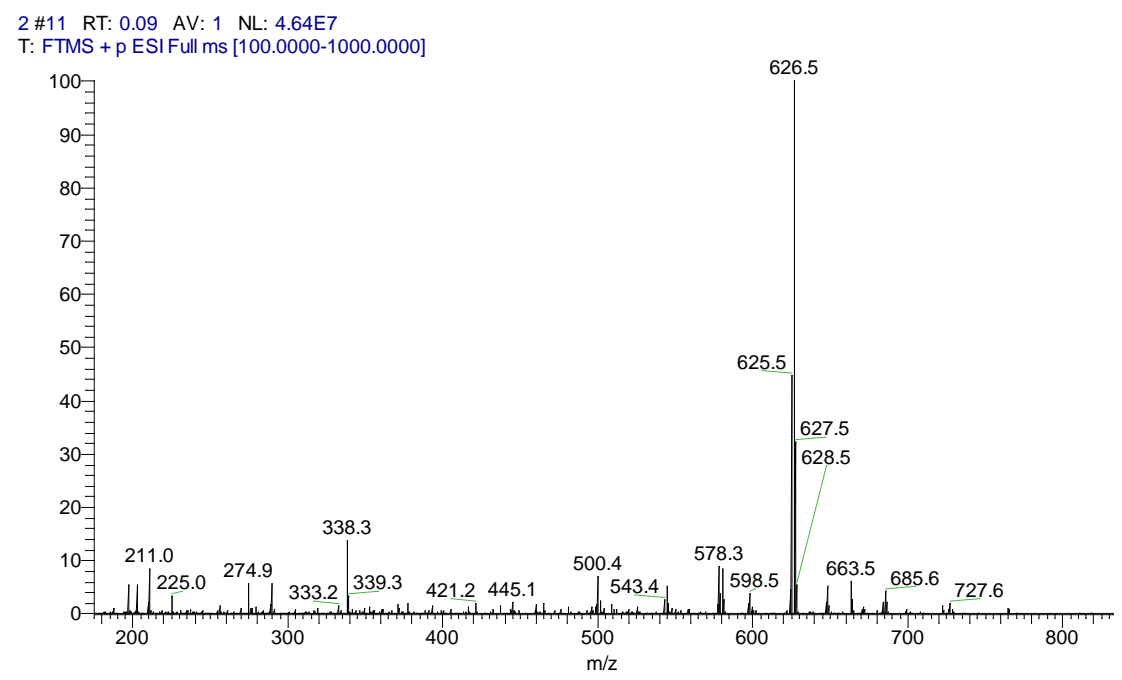

Figure S7. ESI spectrum of compound 6.

Synthesis of 7

A Schlenk tube was charged with 4,4'-(2,2-diphenylethene-1,1-diyl) bis(bromobenzene) (1.47 g, $3 \mathrm{mmol})$, 4-ethynylpyridine hydrochloride (627.75 mg, $4.5 \mathrm{mmol}), \mathrm{Pd}(\mathrm{dppf}) \mathrm{Cl}_{2}(106.5 \mathrm{mg}, 0.15 \mathrm{mmol})$, and $\mathrm{CuI}(28.8 \mathrm{mg}, 0.15 \mathrm{mmol})$. The mixture was placed under nitrogen atmosphere, and anhydrous triethylamine $(15 \mathrm{~mL})$ and 1,4-dioxane $(10 \mathrm{~mL})$ were added by syringe. The reaction was heated at $85{ }^{\circ} \mathrm{C}$ for $48 \mathrm{~h}$ under nitrogen, then cooled down to room temperature and the solvents were 
removed under reduced pressure. The residue was dissolved in dichloromethane (200 $\mathrm{mL})$ and washed by water $(150 \mathrm{~mL})$. After drying over $\mathrm{Na}_{2} \mathrm{SO}_{4}$, the solvent was removed and the residue was purified by column chromatography on silica gel $\left(\mathrm{CH}_{2} \mathrm{Cl}_{2} /\right.$ petroleum ether $\left.=1 / 1\right)$ to afford 7 as a yellow powder. Yield: $690 \mathrm{mg}, 45 \%$. ${ }^{1} \mathrm{H}$ NMR $\left(400 \mathrm{MHz}, \mathrm{CDCl}_{3}, 298 \mathrm{~K}\right) \delta(\mathrm{ppm})=8.67(\mathrm{~s}, 2 \mathrm{H}), 7.4(\mathrm{~s}, 2 \mathrm{H}), 7.31-7.28(\mathrm{~m}$, 2H), 7.25-7.23 (m, 1H), 7.15-6.99 (m, 14H), 6.91-6.87 (m, 1H). ${ }^{13} \mathrm{C}$ NMR (101 MHz, $\left.\mathrm{CDCl}_{3}\right) \delta 149.69,144.51,143.04,142.98,142.73,142.17,138.76,133.01,131.50$, 131.38, 131.24, 131.21, 131.06, 127.96, 127.93, 127.00, 120.80, 120.12, 94.13, 87.07. ESI-MS: m/z Calcd for $\mathrm{C}_{33} \mathrm{H}_{22} \mathrm{BrN}[\mathrm{M}+\mathrm{H}]^{+}$512.1, found 512.1.

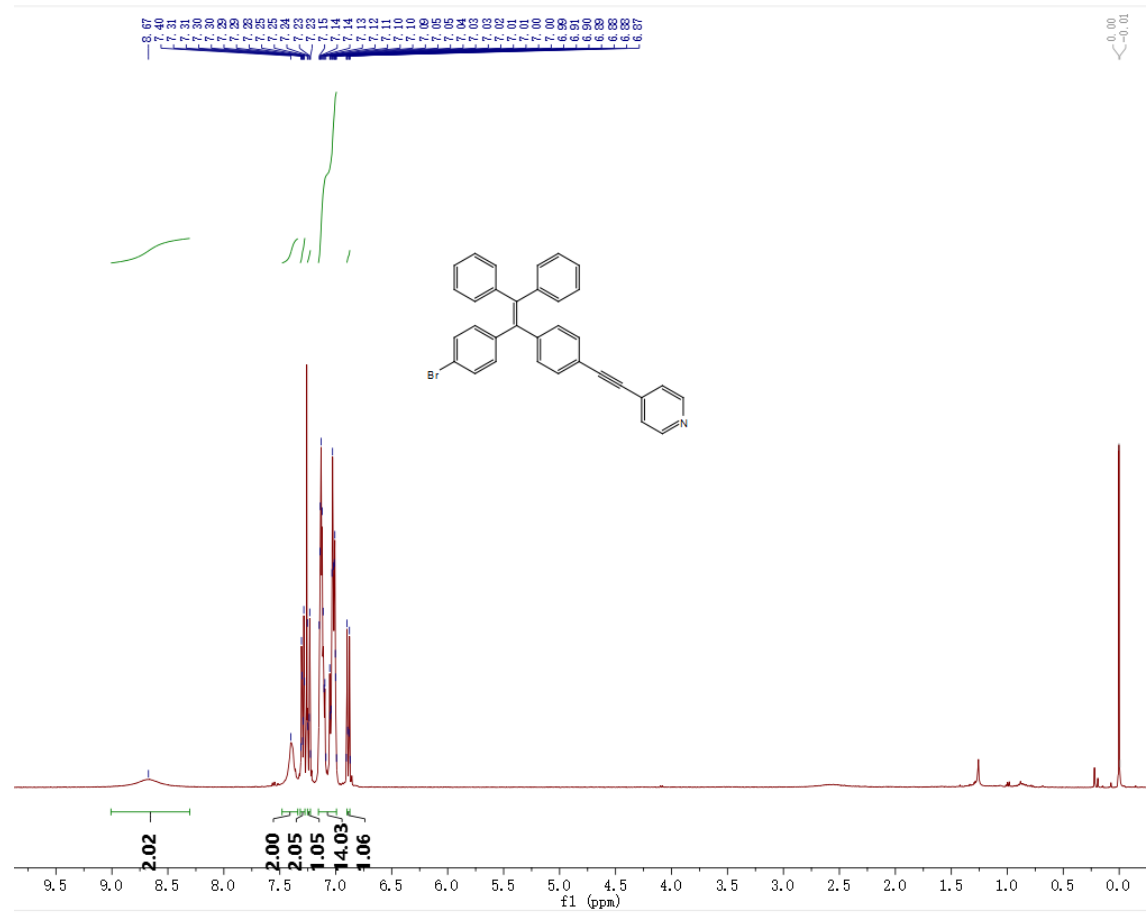

Figure S8. ${ }^{1} \mathrm{H}$ NMR spectrum (400 MHz, $\left.\mathrm{CDCl}_{3}, 298 \mathrm{~K}\right)$ of compound 7. 


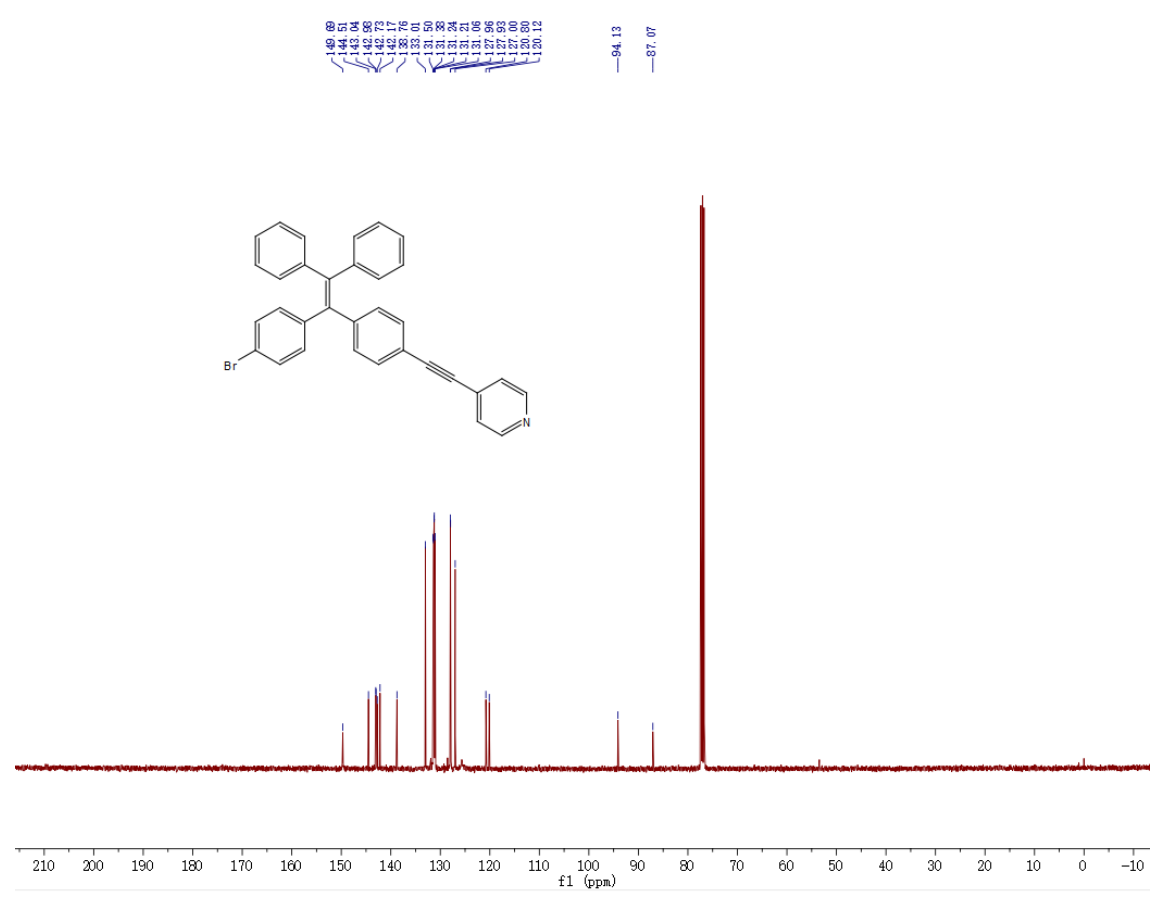

Figure S9. ${ }^{13} \mathrm{C}$ NMR spectrum $\left(101 \mathrm{MHz}, \mathrm{CDCl}_{3}, 298 \mathrm{~K}\right)$ of compound 7.

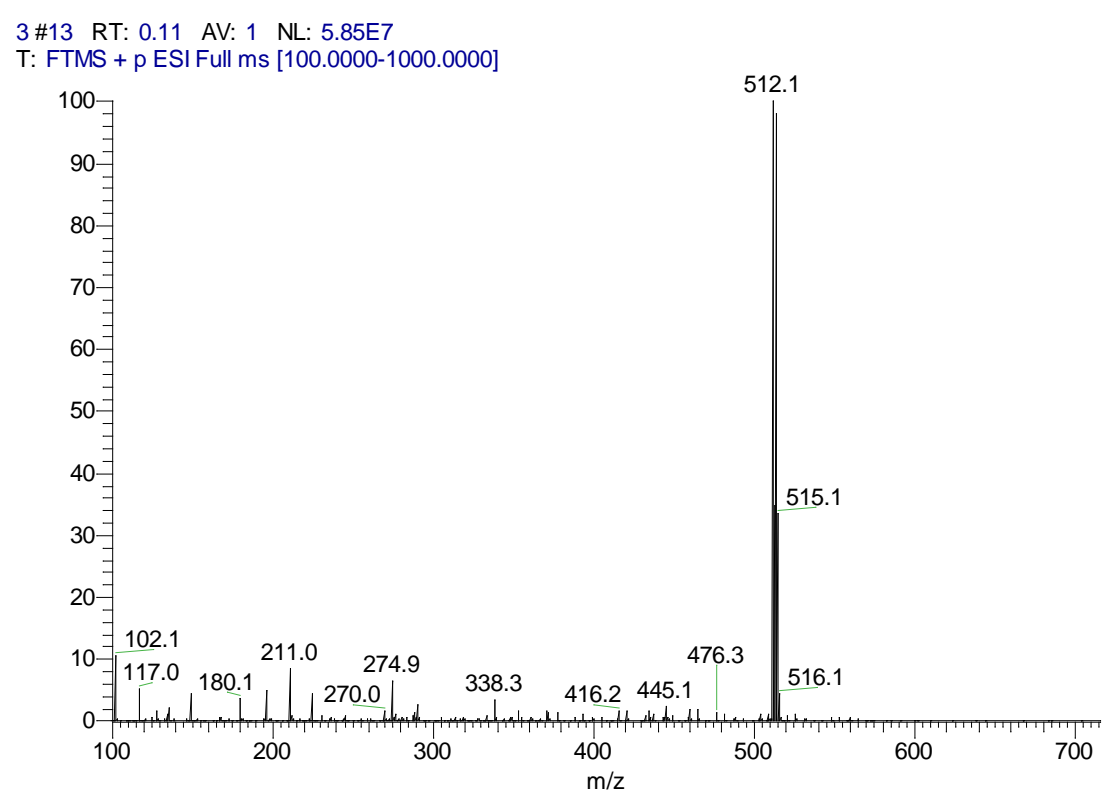

Figure S10. ESI spectrum of compound 7.

Synthesis of $\mathbf{3}$

A Schlenk tube was charged with $6(150 \mathrm{mg}, 0.276 \mathrm{mmol}), 7(350 \mathrm{mg}, 0.68$ $\mathrm{mmol})$, and $\mathrm{Pd}\left(\mathrm{PPh}_{3}\right)_{4}(30 \mathrm{mg}, 0.024 \mathrm{mmol})$. The mixture was placed under nitrogen atmosphere, and degassed $\mathrm{K}_{2} \mathrm{CO}_{3}(2 \mathrm{~mol} / \mathrm{L}, 0.66 \mathrm{~mL})$, degassed THF $(20 \mathrm{~mL})$ and degassed toluene $(10 \mathrm{~mL})$ were added by syringe. The reaction was stirred at $80{ }^{\circ} \mathrm{C}$ 
for $48 \mathrm{~h}$ under nitrogen, then cooled down to room temperature and the solvents were removed under reduced pressure. The residue was dissolved in dichloromethane (200 $\mathrm{mL})$ and washed successively by water $(150 \mathrm{~mL})$. After drying over $\mathrm{Na}_{2} \mathrm{SO}_{4}$, the solvent was removed and the residue was purified by column chromatography on silica gel $\left.\left(\mathrm{CH}_{2} \mathrm{Cl}_{2} / \mathrm{MeOH}\right)=100 / 1\right)$ to afford $\mathbf{3}$ as a yellow powder. Yield: $112 \mathrm{mg}$, 33\%. ${ }^{1} \mathrm{H}$ NMR $\left(400 \mathrm{MHz}, \mathrm{CDCl}_{3}, 298 \mathrm{~K}\right) \delta(\mathrm{ppm})=8.60(\mathrm{~s}, 4 \mathrm{H}), 7.84(\mathrm{~d}, J=1.52 \mathrm{~Hz}$, 2H), $7.81(\mathrm{~s}, 1 \mathrm{H}), 7.44-7.39(\mathrm{~m}, 8 \mathrm{H}), 7.33-7.31(\mathrm{~m}, 4 \mathrm{H}), 7.16-7.04(\mathrm{~m}, 28 \mathrm{H}), 6.17(\mathrm{t}$, $J=5.8 \mathrm{~Hz}, 1 \mathrm{H}), 3.47(\mathrm{q}, J=6.72 \mathrm{~Hz}, 2 \mathrm{H}), 1.66-1.59(\mathrm{~m}, 2 \mathrm{H}), 1.35-1.25(\mathrm{~m}, 30 \mathrm{H})$, $0.87(\mathrm{t}, J=6.64 \mathrm{~Hz}, 3 \mathrm{H}) .{ }^{13} \mathrm{C} \mathrm{NMR}\left(101 \mathrm{MHz}, \mathrm{CDCl}_{3}, 298 \mathrm{~K}\right) \delta(\mathrm{ppm}) 167.49,149.65$, $144.96,143.29,143.26,142.92,142.53,141.54,139.40,138.28,136.05,131.95$, 131.59 , 131.36, 131.34, 131.31, 128.28, 127.91, 126.89, 126.58, 125.52, 124.26, 119.97, 94.33, 86.97, 40.30, 31.94, 29.72, 29.68, 29.64, 29.59, 29.38, 27.07, 22.71, 14.15. ESI-MS: m/z Calcd for $\mathrm{C}_{91} \mathrm{H}_{85} \mathrm{~N}_{3} \mathrm{O}[\mathrm{M}+\mathrm{H}]^{+}$1236.7, found 1236.7 .

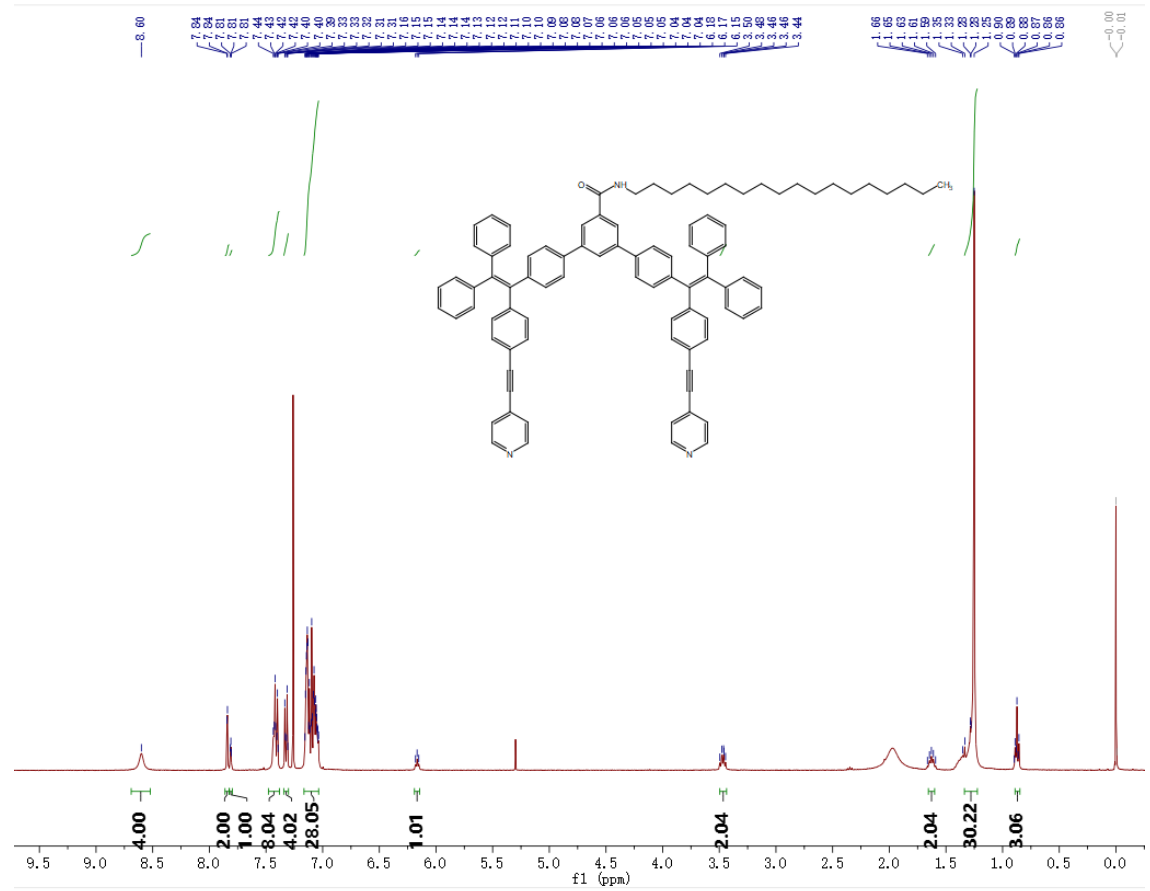

Figure S11. ${ }^{1} \mathrm{H}$ NMR spectrum (400 MHz, $\left.\mathrm{CDCl}_{3}, 298 \mathrm{~K}\right)$ of compound 3. 


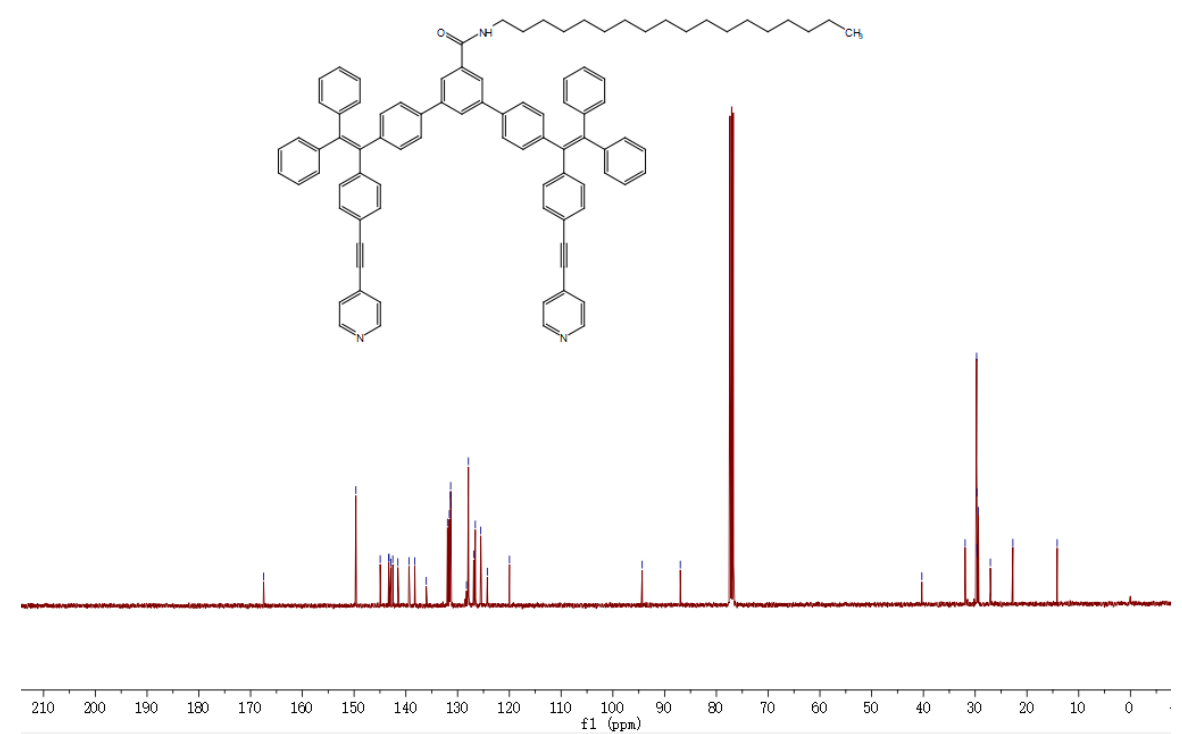

Figure S12. ${ }^{13} \mathrm{C}$ NMR spectrum $\left(101 \mathrm{MHz}, \mathrm{CDCl}_{3}, 298 \mathrm{~K}\right)$ of compound 3.

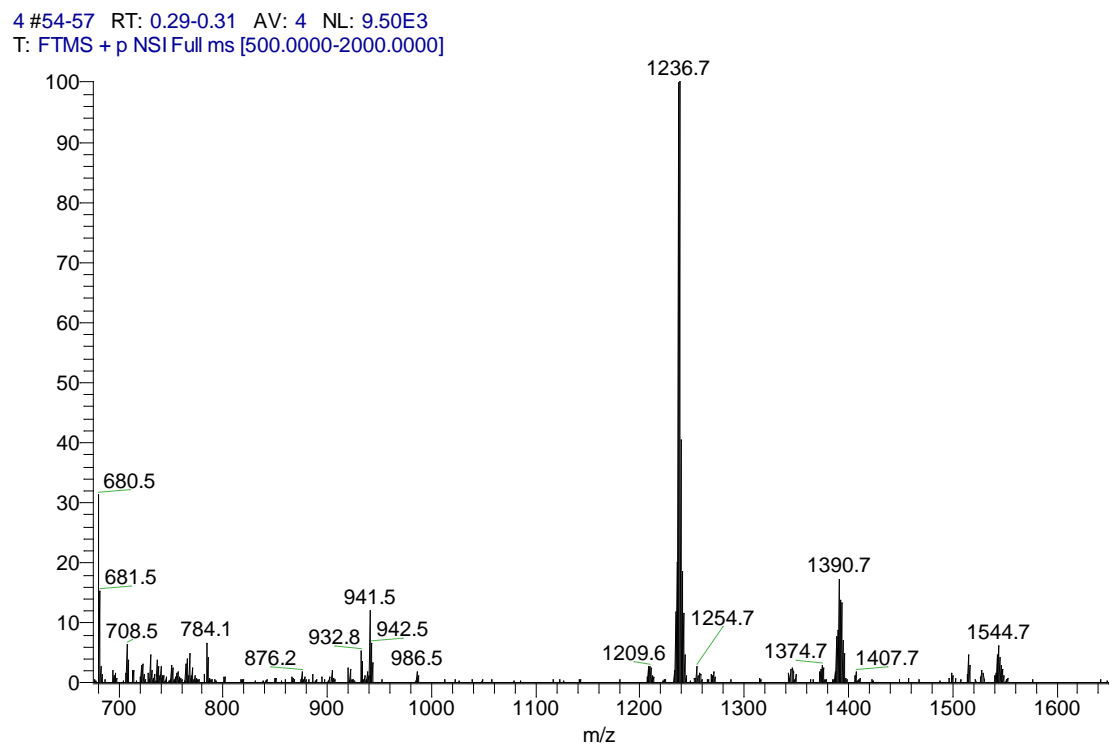

Figure S13. ESI spectrum of compound 3.

\section{Synthesis of M1}

$3(6.18 \mathrm{mg}, 5 \mu \mathrm{mol}), 4(3.64 \mathrm{mg}, 5 \mu \mathrm{mol})$ were mixed in a $1: 1$ molar ratio and dissolved in dichloromethane $(3 \mathrm{~mL})$. The reaction mixture was stirred at room temperature for $12 \mathrm{~h}$. The solvent was removed by nitrogen flow to almost give M1 quantitatively as a yellow powder. ${ }^{1} \mathrm{H}$ NMR $\left(400 \mathrm{MHz}, \mathrm{CD}_{2} \mathrm{Cl}_{2}, 298 \mathrm{~K}\right) \delta(\mathrm{ppm})=$ $9.06(\mathrm{~d}, J=4.56 \mathrm{~Hz}, 8 \mathrm{H}), 7.74(\mathrm{~d}, J=1.52 \mathrm{~Hz}, 4 \mathrm{H}), 7.50(\mathrm{~s}, 2 \mathrm{H}), 7.46(\mathrm{~d}, \mathrm{~J}=6.36 \mathrm{~Hz}$, 
8H), 7.25-7.22 (m, 16H), 7.13-7.11 (m, 8H), 7.09-7.00 (m, 32H), 6.96-6.93 (m, 8H), 6.89-6.87 (m, 8H), $6.19(\mathrm{t}, J=5.56 \mathrm{~Hz}, 2 \mathrm{H}), 3.36(\mathrm{q}, J=6.76 \mathrm{~Hz}, 4 \mathrm{H}), 1.77-1.71(\mathrm{~m}$, 28H), $1.50(\mathrm{~s}, 36 \mathrm{H}), 1.29-1.17(\mathrm{~m}, 60 \mathrm{H}), 0.81-0.78(\mathrm{t}, J=6.64 \mathrm{~Hz}, 6 \mathrm{H}) .{ }^{31} \mathrm{P}$ NMR $\left(121.4 \mathrm{MHz}, \mathrm{CD}_{2} \mathrm{Cl}_{2}\right) \delta(\mathrm{ppm})-3.14\left(\mathrm{~s},{ }^{195} \mathrm{Pt}\right.$ satellites, $\left.{ }^{1} J_{\mathrm{Pt}-\mathrm{P}}=2336.95 \mathrm{~Hz}\right)$. ESI-TOF-MS: $\mathrm{C}_{210} \mathrm{H}_{230} \mathrm{~F}_{12} \mathrm{~N}_{6} \mathrm{O}_{14} \mathrm{P}_{4} \mathrm{Pt}_{2} \mathrm{~S}_{4} \mathrm{~m} / \mathrm{z}$ [M-3OTf] ${ }^{3+} 1161.53$.

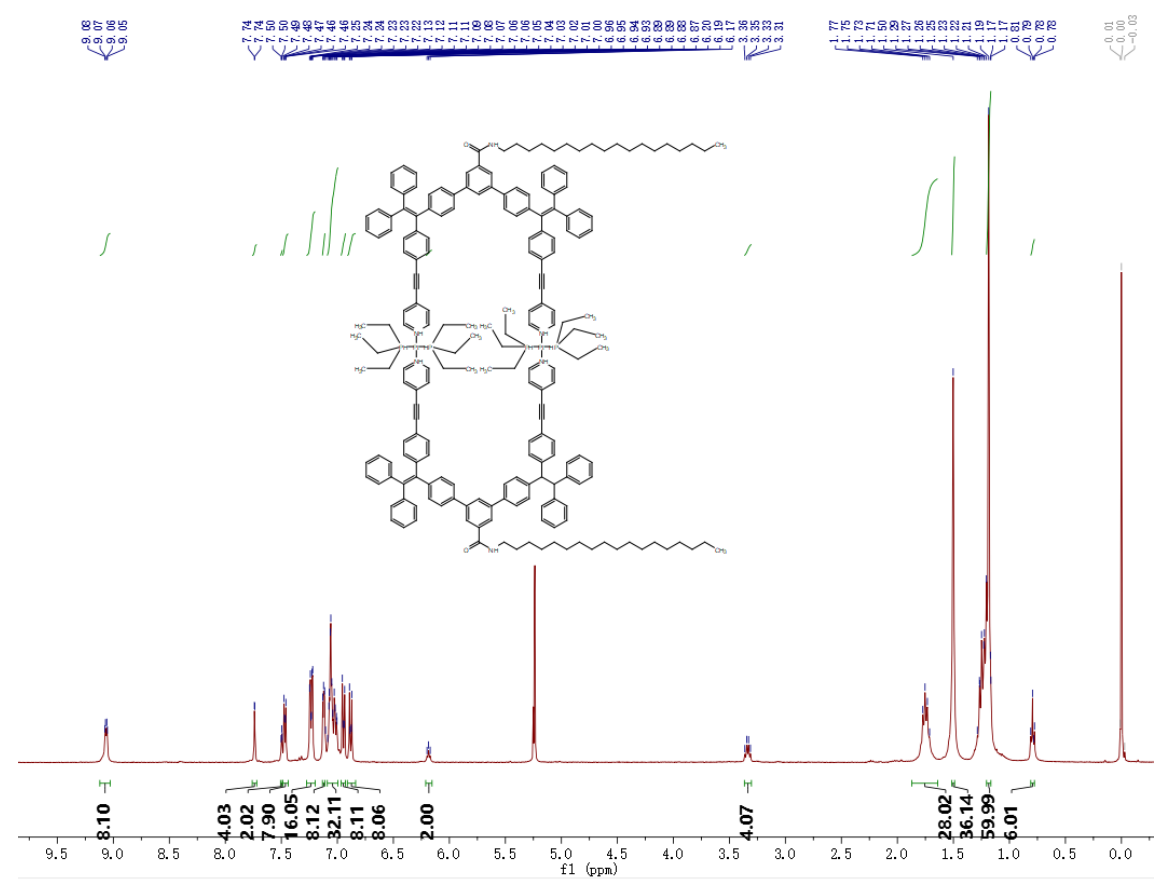

Figure S14. ${ }^{1} \mathrm{H}$ NMR spectrum (400 MHz, $\left.\mathrm{CD}_{2} \mathrm{Cl}_{2}, 298 \mathrm{~K}\right)$ of compound M1.

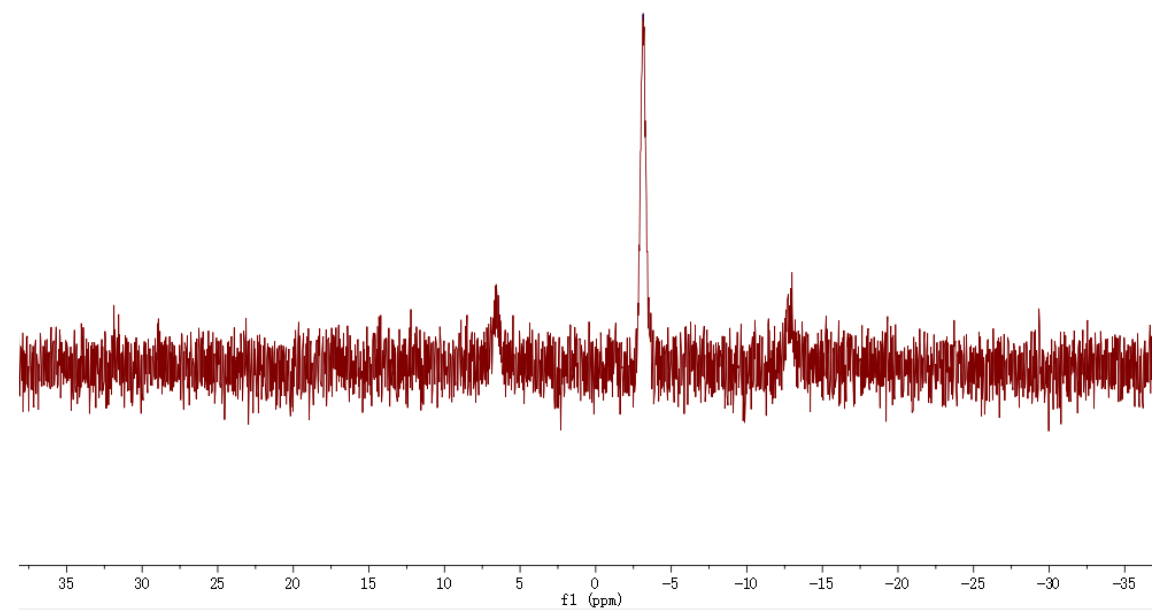

Figure S15. ${ }^{31} \mathrm{P}$ NMR spectrum (121.4 MHz, $\left.\mathrm{CD}_{2} \mathrm{Cl}_{2}, 298 \mathrm{~K}\right)$ of compound M1. 


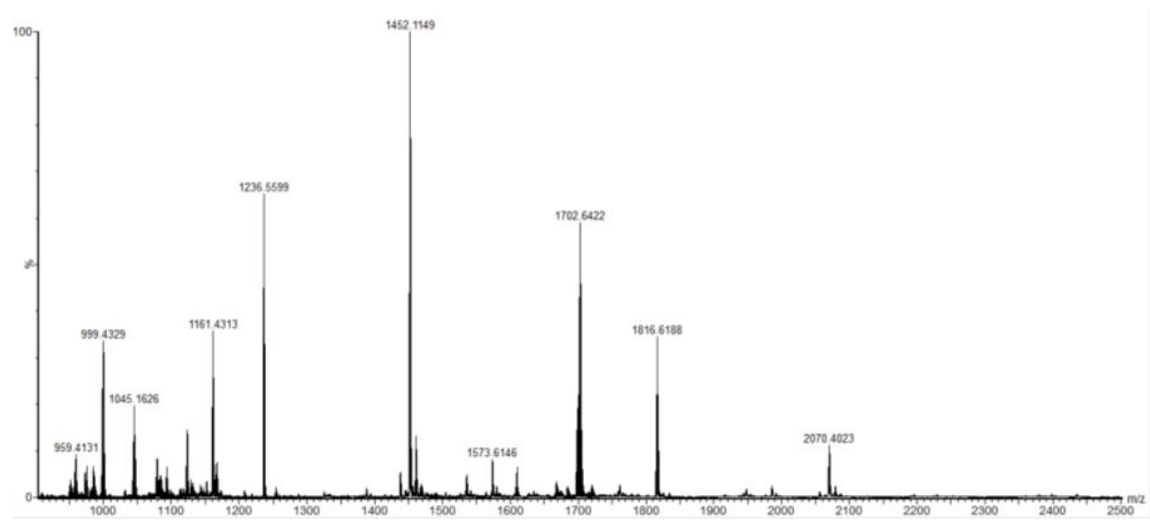

Figure S16. ESI-TOF-MS of M1.

\section{Synthesis of M2}
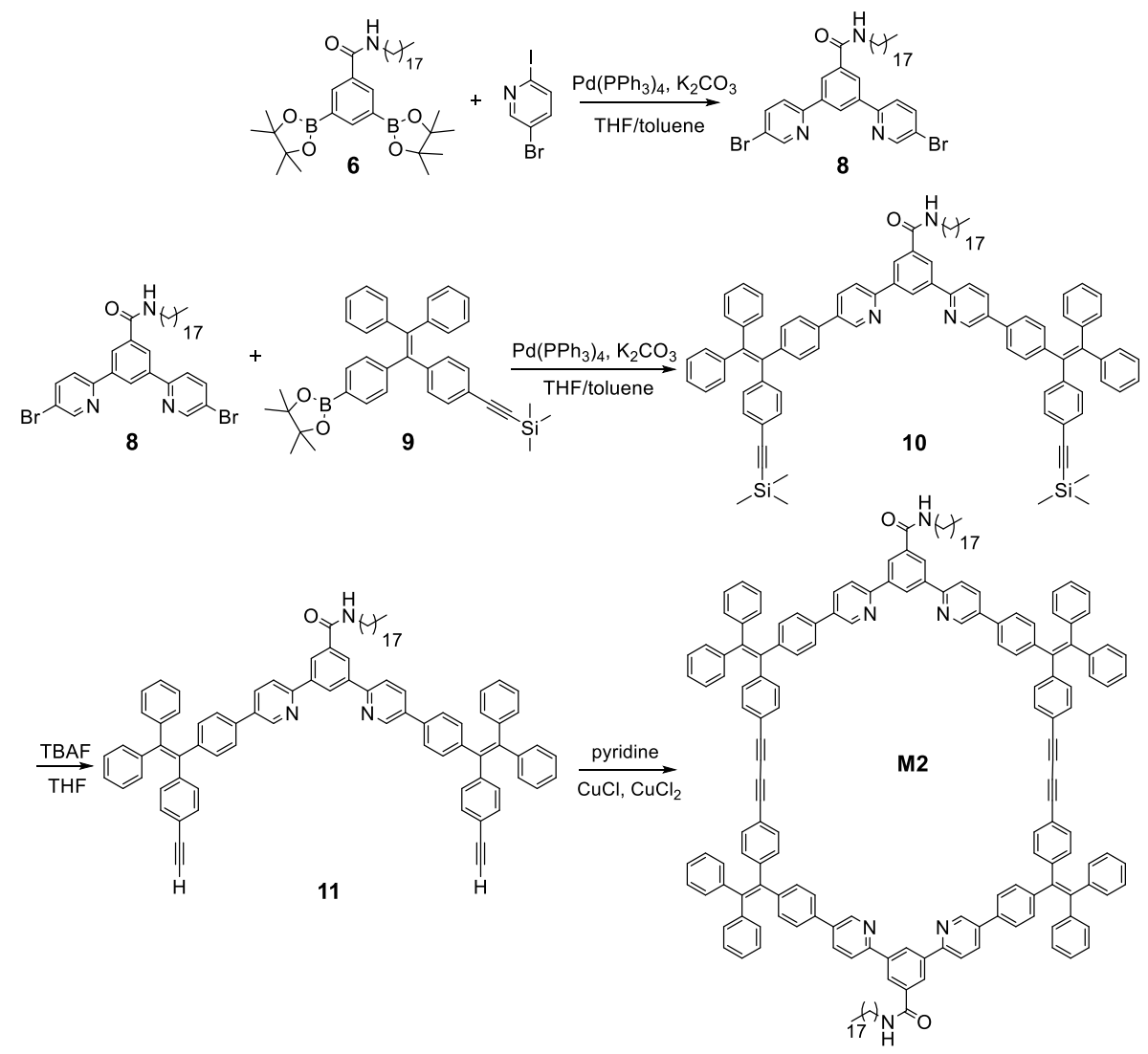

Figure S17. Synthesis route of M2.

Synthesis of $\mathbf{8}$

A Schlenk tube was charged with $6(900 \mathrm{mg}, 1.66 \mathrm{mmol})$, 5-bromo-2-iodopyridine $(1.17 \mathrm{~g}, 4.15 \mathrm{mmol})$, and $\mathrm{Pd}\left(\mathrm{PPh}_{3}\right)_{4}(179 \mathrm{mg}, 0.17 \mathrm{mmol})$. 
The mixture was placed under nitrogen atmosphere, and degassed $\mathrm{K}_{2} \mathrm{CO}_{3}(2 \mathrm{~mol} / \mathrm{L}$, $8.5 \mathrm{~mL})$, degassed THF (40 mL) and degassed toluene $(20 \mathrm{~mL})$ were added by syringe. The reaction was stirred at $80{ }^{\circ} \mathrm{C}$ for $48 \mathrm{~h}$ under nitrogen, then cooled down to room temperature and the solvents were removed under reduced pressure. The residue was dissolved in dichloromethane $(200 \mathrm{~mL})$ and washed successively by water $(150 \mathrm{~mL})$. After drying over $\mathrm{Na}_{2} \mathrm{SO}_{4}$, the solvent was removed and the residue was purified by column chromatography on silica gel (ethyl acetate/petroleum ether $=4 / 1$ ) to afford 8 as a white powder. Yield: $397 \mathrm{mg}, 35 \% .{ }^{1} \mathrm{H}$ NMR $\left(400 \mathrm{MHz}, \mathrm{CDCl}_{3}, 298 \mathrm{~K}\right) \delta(\mathrm{ppm})$ $=8.76-8.74(\mathrm{~m}, 3 \mathrm{H}), 8.44(\mathrm{~d}, \mathrm{~J}=1.6 \mathrm{~Hz}, 2 \mathrm{H}), 7.93(\mathrm{dd}, \mathrm{J}=8.48,2.36 \mathrm{~Hz}, 2 \mathrm{H}), 7.8(\mathrm{~d}$, $\mathrm{J}=8.44 \mathrm{~Hz}, 2 \mathrm{H}), 6.51(\mathrm{t}, \mathrm{J}=5.36 \mathrm{~Hz}, 1 \mathrm{H}), 3.5(\mathrm{q}, \mathrm{J}=7 \mathrm{~Hz}, 2 \mathrm{H}), 1.69-1.62(\mathrm{~m}, 2 \mathrm{H})$, 1.40-1.25 (m, 30H), $0.88(\mathrm{t}, \mathrm{J}=7.04 \mathrm{~Hz}, 3 \mathrm{H}) .{ }^{13} \mathrm{C} \mathrm{NMR}\left(101 \mathrm{MHz}, \mathrm{CDCl}_{3}, 298 \mathrm{~K}\right) \delta$ (ppm) 166.80, 154.31, 150.63, 139.76, 138.98, 136.23, 127.62, 125.98, 122.02, 120.16, 40.39, 31.95, 29.73, 29.65, 29.60, 29.39, 27.09, 24.88, 22.72, 14.16. ESI-MS: $\mathrm{m} / \mathrm{z}$ Calcd for $\mathrm{C}_{35} \mathrm{H}_{47} \mathrm{Br}_{2} \mathrm{~N}_{3} \mathrm{O}[\mathrm{M}+\mathrm{H}]^{+}$686.2, found 686.2.

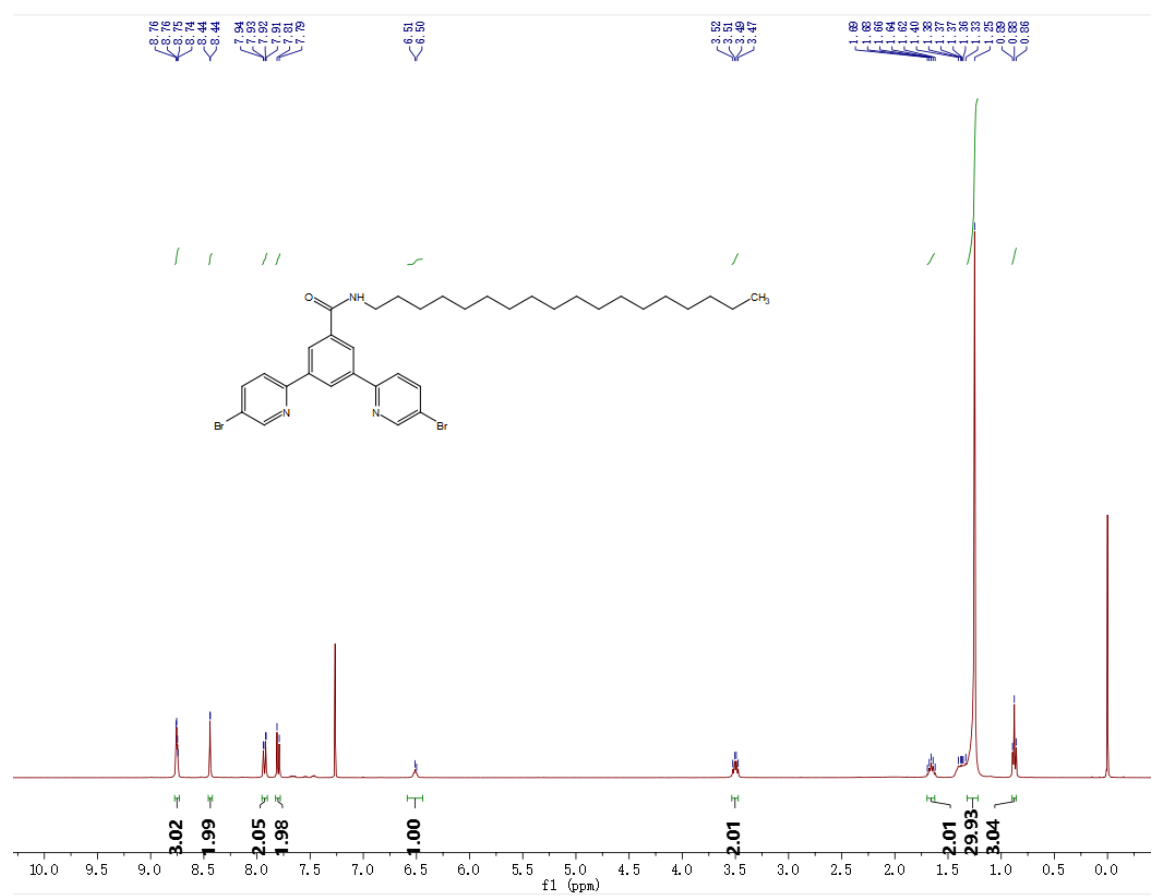

Figure S18. ${ }^{1} \mathrm{H}$ NMR spectrum $\left(400 \mathrm{MHz}, \mathrm{CDCl}_{3}, 298 \mathrm{~K}\right)$ of compound 8. 


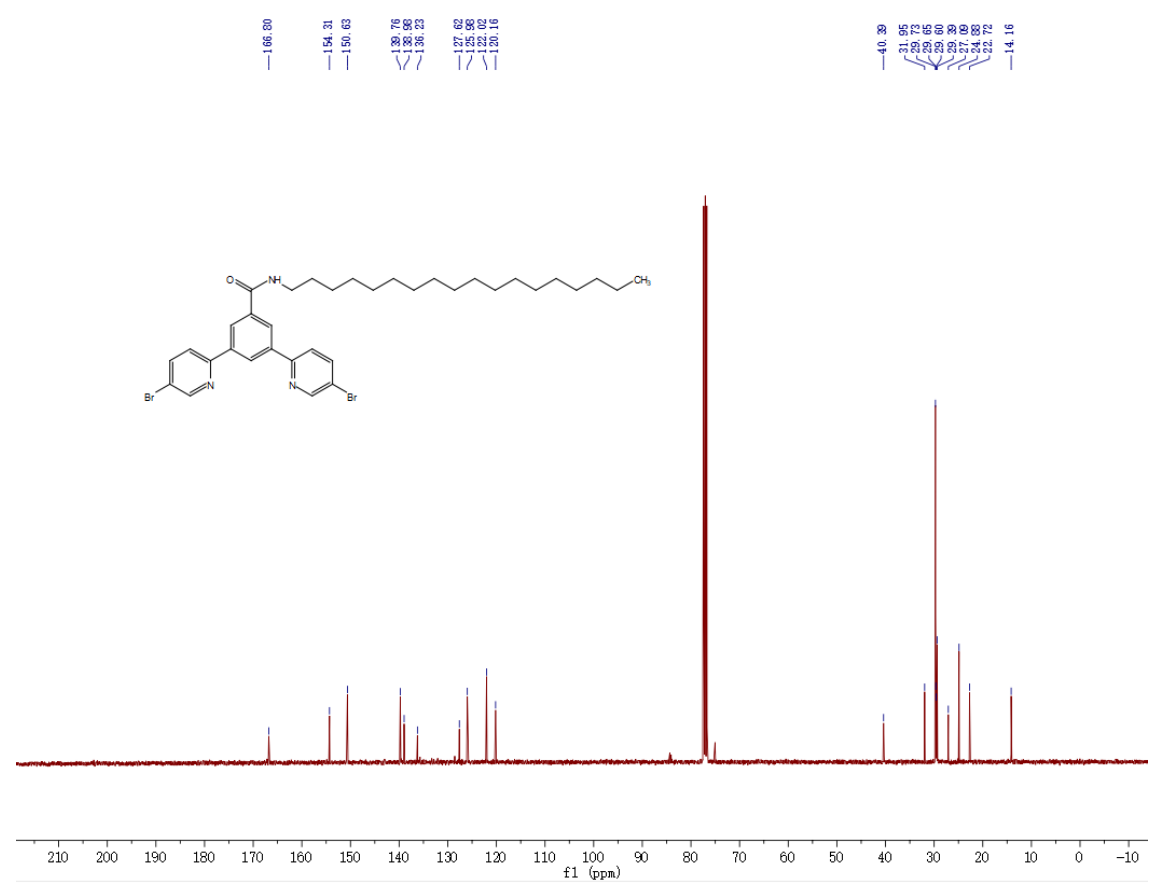

Figure S19. ${ }^{13} \mathrm{C}$ NMR spectrum $\left(101 \mathrm{MHz}, \mathrm{CDCl}_{3}, 298 \mathrm{~K}\right)$ of compound $\mathbf{8}$.

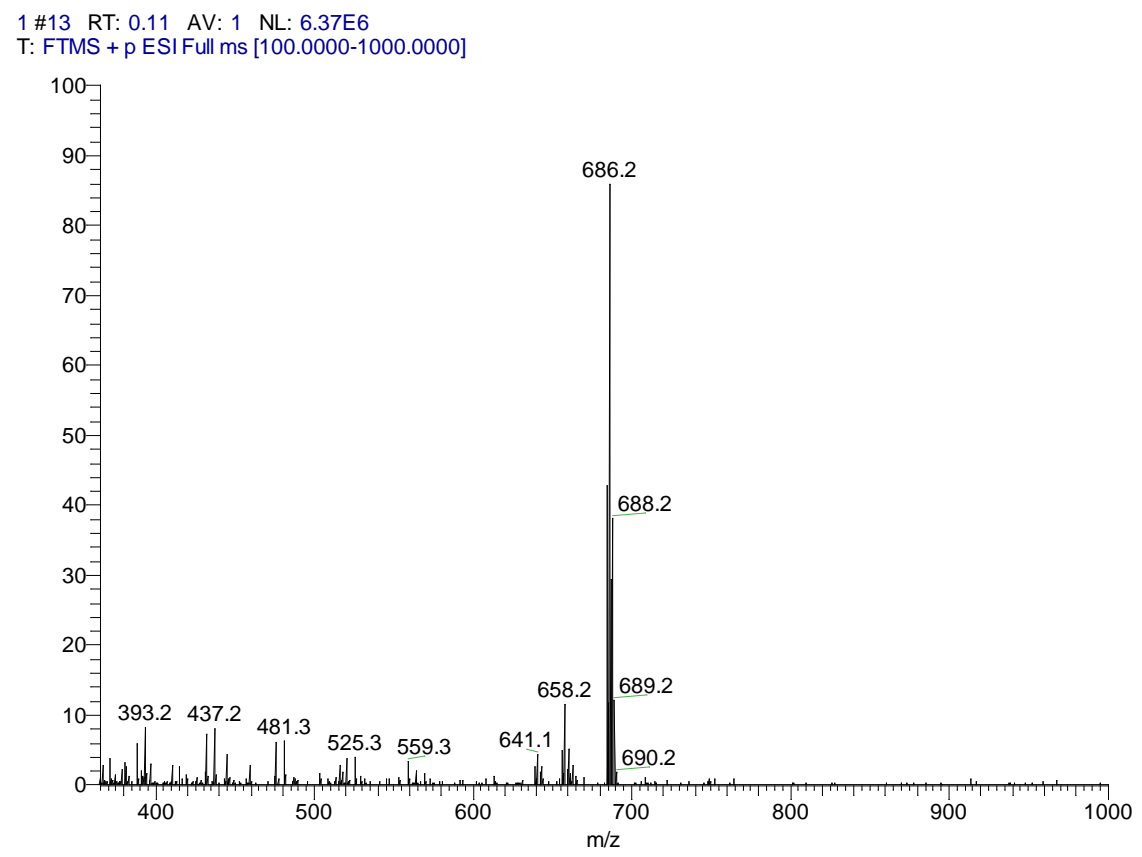

Figure 20. ESI spectrum of compound $\mathbf{8}$.

Synthesis of $\mathbf{1 0}$

A Schlenk tube was charged with 8 (500 mg, $0.73 \mathrm{mmol}), 9$ (930 g, $1.68 \mathrm{mmol})$, and $\mathrm{Pd}\left(\mathrm{PPh}_{3}\right)_{4}(77 \mathrm{mg}, 0.07 \mathrm{mmol})$. The mixture was placed under nitrogen atmosphere, and degassed $\mathrm{K}_{2} \mathrm{CO}_{3}(2 \mathrm{~mol} / \mathrm{L}, 4 \mathrm{~mL})$, degassed THF $(20 \mathrm{~mL})$ and 
degassed toluene $(10 \mathrm{~mL})$ were added by syringe. The reaction was stirred at $80{ }^{\circ} \mathrm{C}$ for $48 \mathrm{~h}$ under nitrogen, then cooled down to room temperature and the solvents were removed under reduced pressure. The residue was dissolved in dichloromethane (200 $\mathrm{mL})$ and washed successively by water $(150 \mathrm{~mL})$. After drying over $\mathrm{Na}_{2} \mathrm{SO}_{4}$, the solvent was removed and the residue was purified by column chromatography on silica gel (ethyl acetate/petroleum ether $=4 / 1$ ) to afford $\mathbf{1 0}$ as a green powder. Yield: $292 \mathrm{mg}, 29 \% .{ }^{1} \mathrm{H} \mathrm{NMR}\left(400 \mathrm{MHz}, \mathrm{CDCl}_{3}, 298 \mathrm{~K}\right) \delta(\mathrm{ppm})=8.93(\mathrm{~s}, 2 \mathrm{H}), 2.89(\mathrm{~s}, 1 \mathrm{H})$, $8.57(\mathrm{~s}, 2 \mathrm{H}), 8.00(\mathrm{~s}, 4 \mathrm{H}), 7.43(\mathrm{~d}, \mathrm{~J}=10 \mathrm{~Hz}, 4 \mathrm{H}), 7.27(\mathrm{~d}, \mathrm{~J}=8.96 \mathrm{~Hz}, 4 \mathrm{H})$, 7.16-7.03 (m, 28H), $6.80(\mathrm{~s}, 1 \mathrm{H}), 3.54(\mathrm{q}, \mathrm{J}=5.92 \mathrm{~Hz}, 2 \mathrm{H}), 1.7-1.69(\mathrm{~m}, 2 \mathrm{H})$, 1.41-1.23 (m, 30H), $0.90(\mathrm{t}, \mathrm{J}=6 \mathrm{~Hz}, 3 \mathrm{H}), 0.26(\mathrm{~s}, 18 \mathrm{H}) .{ }^{13} \mathrm{C} \mathrm{NMR}\left(101 \mathrm{MHz}, \mathrm{CDCl}_{3}\right.$, 298K) $\delta(\mathrm{ppm}) 144.06,143.34,143.28,142.41,139.44,135.18,132.23,131.52$, $131.33,127.93,127.89,126.89,121.14,105.25,94.55,40.41,31.95,29.73,29.69$, 29.39, 22.72, 14.15. ESI-MS: m/z Calcd for $\mathrm{C}_{97} \mathrm{H}_{101} \mathrm{~N}_{3} \mathrm{OSi}_{2}[\mathrm{M}+\mathrm{H}]^{+}$1381.8, found 1381.8 .

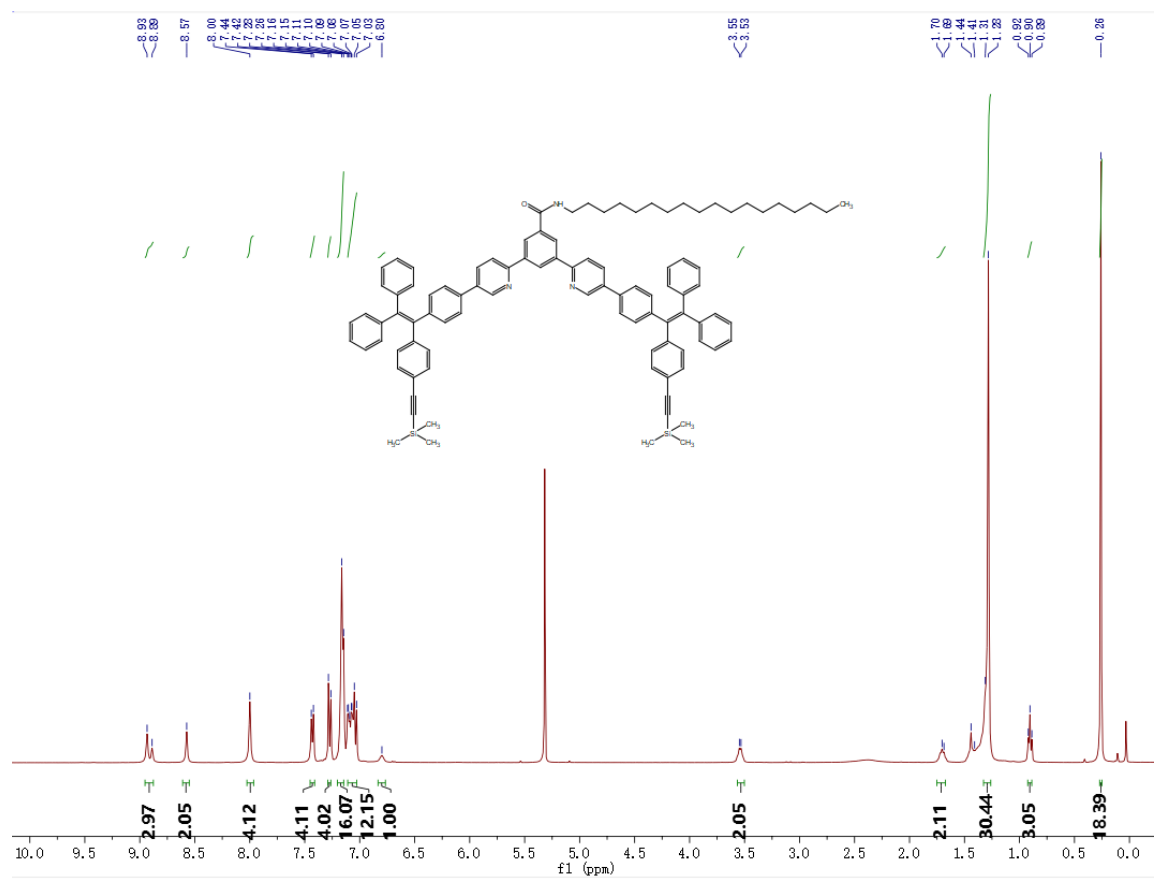

Figure S21. ${ }^{1} \mathrm{H}$ NMR spectrum $\left(400 \mathrm{MHz}, \mathrm{CDCl}_{3}, 298 \mathrm{~K}\right)$ of compound $\mathbf{1 0}$. 


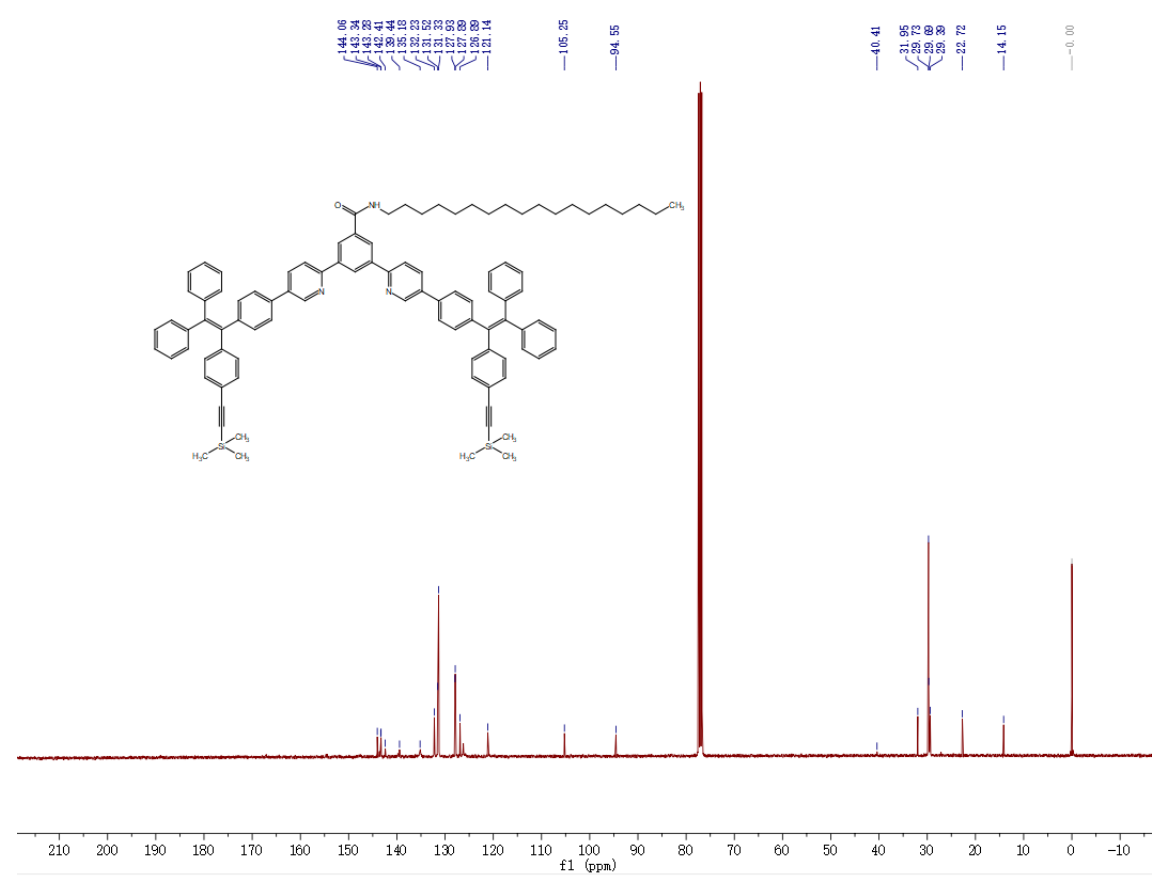

Figure S22. ${ }^{13} \mathrm{C}$ NMR spectrum $\left(101 \mathrm{MHz}, \mathrm{CDCl}_{3}, 298 \mathrm{~K}\right)$ of compound $\mathbf{1 0}$.

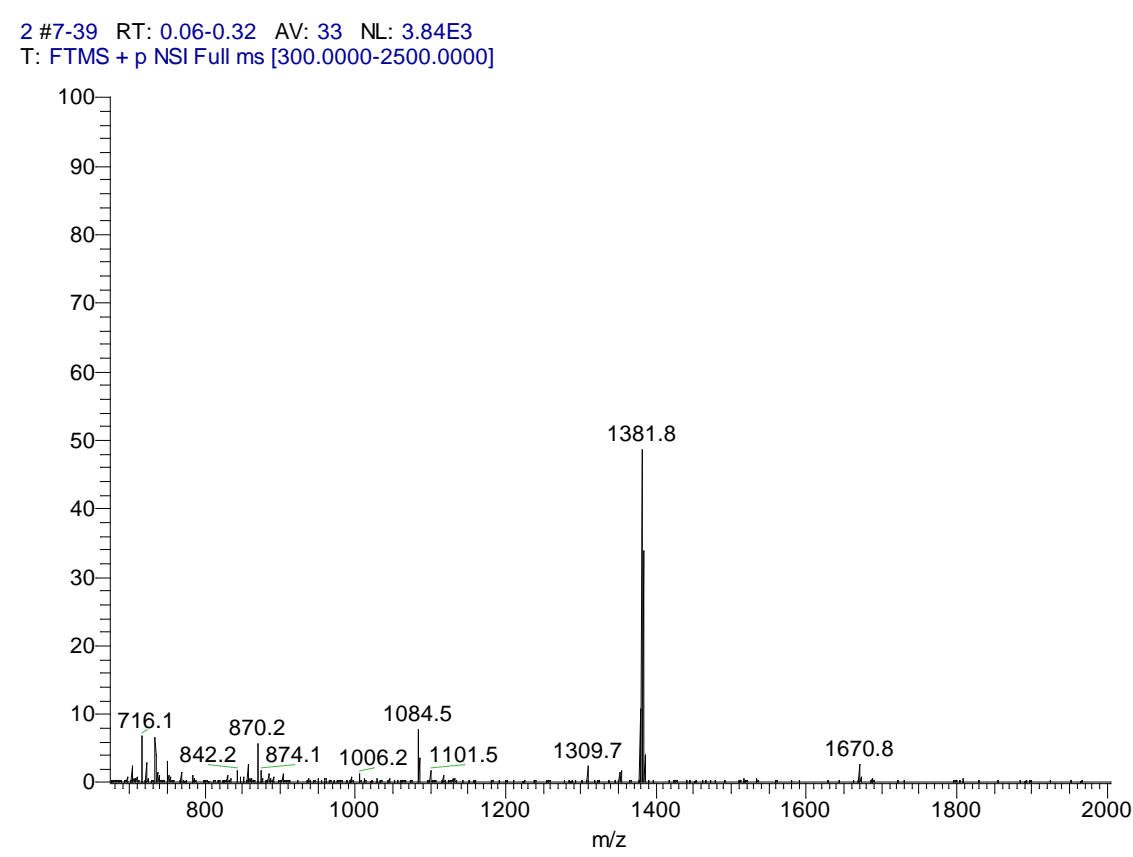

Figure 23. ESI spectrum of compound $\mathbf{1 0}$.

\section{Synthesis of $\mathbf{1 1}$}

10 (150 mg, $0.11 \mathrm{mmol})$ was dissolved in THF (30 mL), tetrabutylammonium fluoride (114 mg, $0.44 \mathrm{mmol})$ was added. Then the reaction was stirred at room temperature for $3 \mathrm{~h}$. The solution was filtered and the solvent was removed by evaporation. The crude product was purified by column chromatography on silica gel 
(ethyl acetate/petroleum ether $=4 / 1$ ) to give $\mathbf{1 1}$ as a green powder. Yield: $122 \mathrm{mg}$, 90\%. ${ }^{1} \mathrm{H}$ NMR $\left(400 \mathrm{MHz}, \mathrm{CDCl}_{3}, 298 \mathrm{~K}\right) \delta(\mathrm{ppm})=8.89(\mathrm{~s}, 3 \mathrm{H}), 8.59$ (s, 2H), 7.99 (s, 4H), $7.39(\mathrm{~s}, 4 \mathrm{H}), 7.26(\mathrm{~d}, \mathrm{~J}=6.68 \mathrm{~Hz}, 4 \mathrm{H}), 7.13-7.03(\mathrm{~m}, 28 \mathrm{H}), 6.94(\mathrm{~s}, 1 \mathrm{H}), 3.51(\mathrm{~s}$, 2H), $3.06(\mathrm{~s}, 2 \mathrm{H}), 1.63(\mathrm{~s}, 2 \mathrm{H}), 1.43-1.25(\mathrm{~m}, 30 \mathrm{H}), 0.87(\mathrm{t}, \mathrm{J}=7 \mathrm{~Hz}, 3 \mathrm{H})$.

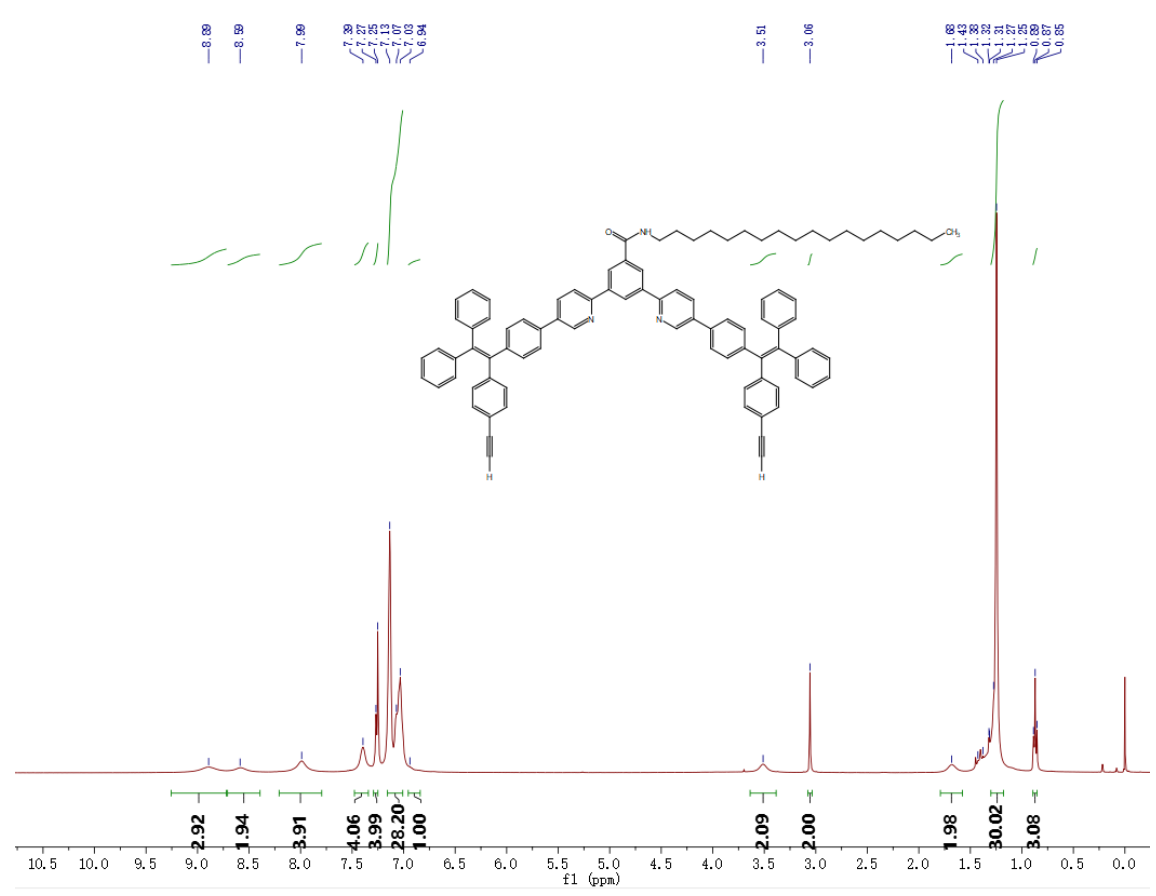

Figure S24. ${ }^{1} \mathrm{H}$ NMR spectrum $\left(400 \mathrm{MHz}, \mathrm{CDCl}_{3}, 298 \mathrm{~K}\right)$ of compound 11.

\section{Synthesis of M2}

$11(100 \mathrm{mg}, 0.081 \mathrm{mmol})$ was dissolved in pyridine $(20 \mathrm{~mL})$ and then was added to a suspension of $\mathrm{CuCl}_{2}(54 \mathrm{mg}, 0.4 \mathrm{mmol})$ and $\mathrm{CuCl}(220 \mathrm{mg}, 2.23 \mathrm{mmol})$ in pyridine $(58 \mathrm{~mL})$. The reaction was stirred over $96 \mathrm{~h}$ at $60{ }^{\circ} \mathrm{C}$, and then was poured into water and extracted with $\mathrm{CH}_{2} \mathrm{Cl}_{2}$. The organic phase was collected and washed with water, ammonium hydroxide (25\%), water, acetic acid $(10 \%)$, water, $\mathrm{NaOH}$ aqueous solution (10\%) and brine, and dried over anhydrous $\mathrm{MgSO}_{4}$. After filtration and evaporation, the crude product was purified by column chromatography on silica gel eluted with ethyl acetate to obtain a slightly yellow powder. The powder was subjected to preparative $\mathrm{GPC}\left(\mathrm{CHCl}_{3}\right.$ as eluent solution) to give $\mathbf{M 2}$ as a yellow powder. Yield: $35 \mathrm{mg}, 90 \% .{ }^{1} \mathrm{H}$ NMR $\left(400 \mathrm{MHz}, \mathrm{CDCl}_{3}, 298 \mathrm{~K}\right) \delta(\mathrm{ppm})=8.90(\mathrm{~s}$, 4H), 8.87 (s, 2H), 8.53 (s, 4H), $7.97(\mathrm{~s}, 8 \mathrm{H}), 7.41(\mathrm{~d}, \mathrm{~J}=7.8 \mathrm{~Hz}, 8 \mathrm{H}), 7.27$ (d, J = 8.2 
$\mathrm{Hz}, 8 \mathrm{H}), 7.15-7.02(\mathrm{~m}, 56 \mathrm{H}), 6.72(\mathrm{~s}, 2 \mathrm{H}), 3.52(\mathrm{q}, \mathrm{J}=5.88 \mathrm{~Hz}, 4 \mathrm{H}), 1.70-1.66(\mathrm{~m}$, $4 \mathrm{H}), 1.41-1.25(\mathrm{~m}, 60 \mathrm{H}), 0.87(\mathrm{t}, \mathrm{J}=6.24 \mathrm{~Hz}, 6 \mathrm{H}) .{ }^{13} \mathrm{C} \mathrm{NMR}\left(101 \mathrm{MHz}, \mathrm{CDCl}_{3}\right.$, $298 \mathrm{~K}) \delta(\mathrm{ppm}) 143.81,142.48,142.18,142.12,141.66,138.22,134.16,131.21$, 130.97, 130.49, 130.29, 126.91, 125.97, 125.26, 118.76, 80.82, 73.34, 39.38, 30.91, $28.69,28.64,28.58, \quad 28.38,28.34,26.10, \quad 21.67$, 13.10. MALDI-TOF-MS: $\mathrm{C}_{182} \mathrm{H}_{166} \mathrm{~N}_{6} \mathrm{O}_{2} \mathrm{~m} / \mathrm{z}[\mathrm{M}+\mathrm{H}]^{+}$2469.3700, found 2469.3708; [M+Na $]^{+}$2492.3598, found 2492.3590; $[\mathrm{M}+\mathrm{K}]^{+}$2508.4683, found 2508.4678.

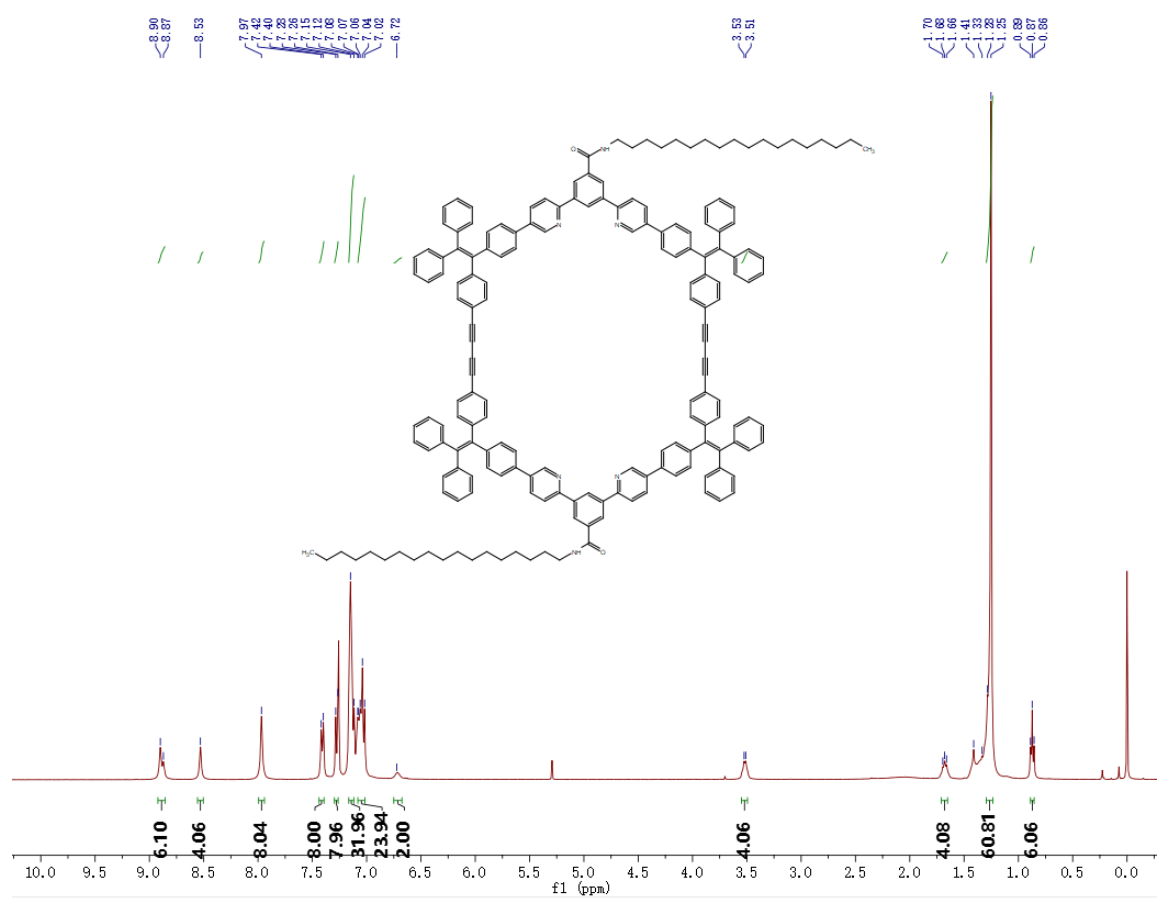

Figure S25. ${ }^{1} \mathrm{H}$ NMR spectrum $\left(400 \mathrm{MHz}, \mathrm{CDCl}_{3}, 298 \mathrm{~K}\right)$ of compound M2. 


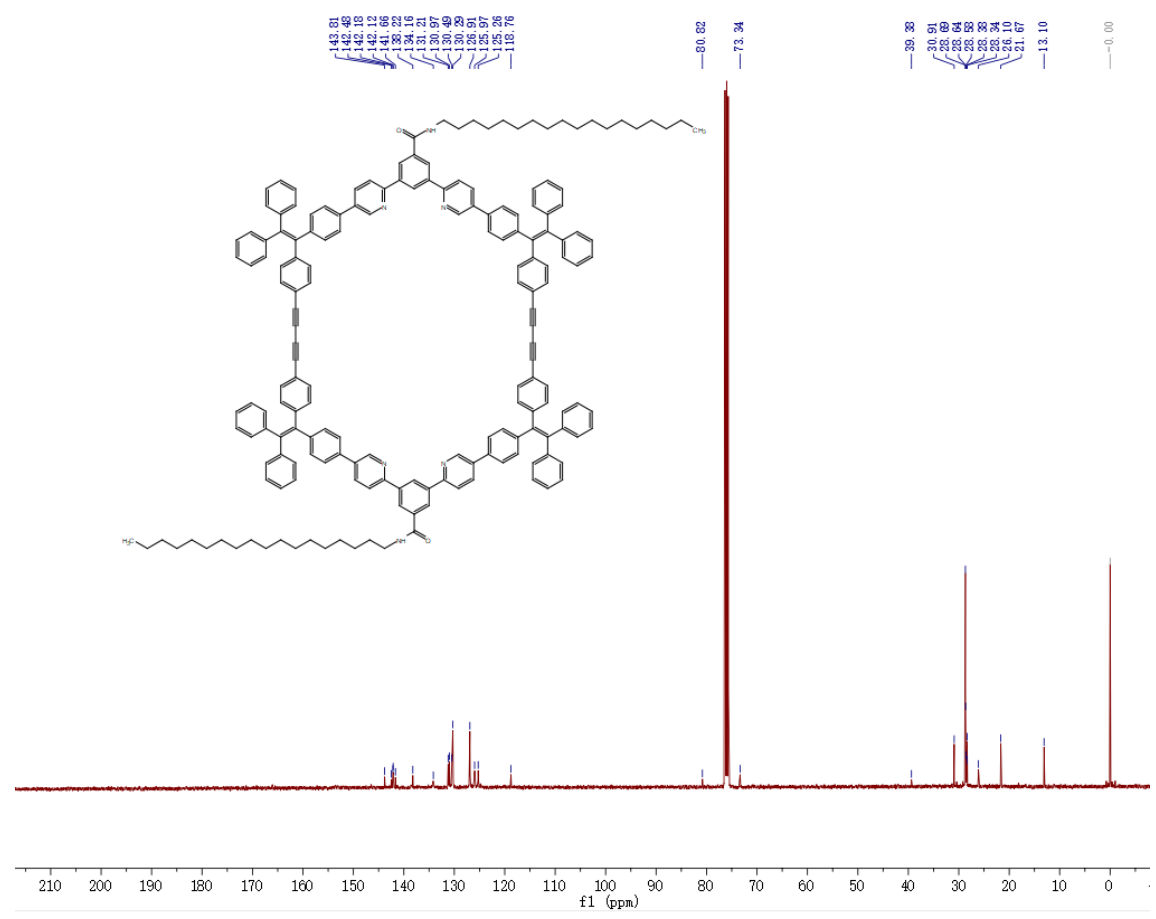

Figure S26. ${ }^{13} \mathrm{C}$ NMR spectrum $\left(101 \mathrm{MHz}, \mathrm{CDCl}_{3}, 298 \mathrm{~K}\right)$ of compound $\mathbf{M 2}$.

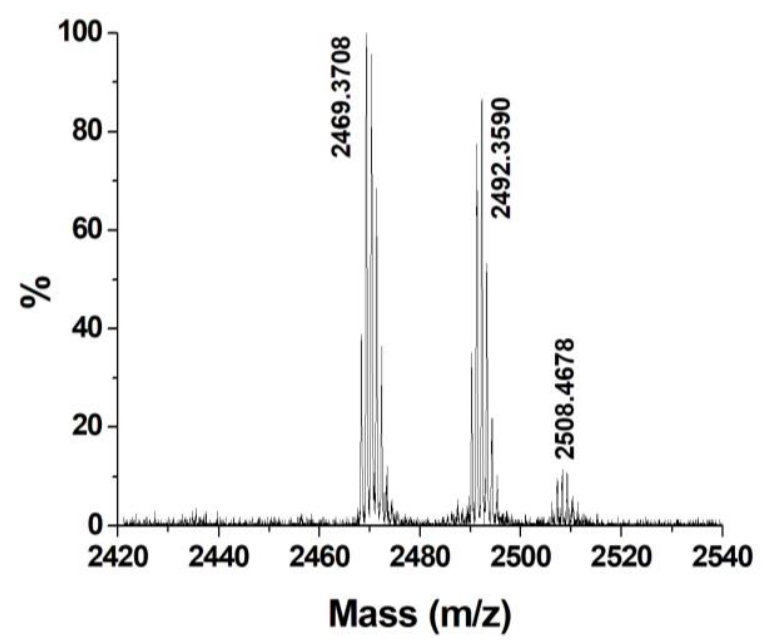

Figure S27. MALDI-TOF-MS of M2. 


\section{Experimental procedure and methods}

\subsection{The preparation of the samples}

The preparation process for the assembly: the stock solution of M1 $\left(2 \times 10^{-4} \mathrm{M}\right.$, dissolved in $\mathrm{MeOH})$, ESY $\left(1 \times 10^{-5} \mathrm{M}\right.$, dissolved in $\left.\mathrm{H}_{2} \mathrm{O}-\mathrm{CH}_{3} \mathrm{OH}, \mathrm{v} / \mathrm{v} ; 19: 1\right)$, SR101 $\left(1 \times 10^{-5} \mathrm{M}\right.$, dissolved in $\left.\mathrm{H}_{2} \mathrm{O}-\mathrm{CH}_{3} \mathrm{OH}, \mathrm{v} / \mathrm{v} ; 19: 1\right)$ were prepared, respectively. M1 assembly were prepared as follows: $0.2 \mathrm{~mL}$ of $\mathbf{M 1}$ stock solutions were added into 3.8 $\mathrm{mL}$ of water under vigorous stirring to afford $1 \times 10^{-5} \mathrm{M}$ solution $\left(\mathrm{H}_{2} \mathrm{O}-\mathrm{CH}_{3} \mathrm{OH}\right.$, v/v; 19:1). M1-ESY assembly were prepared as follows: $20 \mu \mathrm{L}$ of ESY stock solutions were added into $2 \mathrm{~mL}$ of M1 assembly. M1-SR101 assembly were prepared as follows: $20 \mu \mathrm{L}$ of SR101 stock solutions were added into $2 \mathrm{~mL}$ of $\mathbf{M 1}$ assembly. M1-ESY-SR101 assembly were prepared as follows: $8 \mu \mathrm{L}$ of SR101 solution were added into $2 \mathrm{~mL}$ of M1-ESY assembly (100:1).

The PL tests in Figure 3 are as follows: the ESY and SR101 was dissolved in $\mathrm{H}_{2} \mathrm{O}-\mathrm{CH}_{3} \mathrm{OH}(19: 1 ; \mathrm{v} / \mathrm{v})$ and added into the methanol/water mixtures of M1 or M1-ESY assembly (100:1).

\subsection{Energy transfer efficiency ( $\left.\Phi_{\mathrm{ET}}\right)$ calculation}

The energy-transfer efficiency ( $\left.\Phi_{\mathrm{ET}}\right)$ was calculated using equation $\mathrm{S} 1$ :

$$
\Phi_{E T}=1-I_{D A},(\lambda e x=\text { donor }) / I_{D},(\lambda e x=\text { donor })
$$

For M1-ESY system, where $\mathbf{I}_{\mathbf{D A}}$ and $\mathbf{I}_{\mathbf{D}}$ are the fluorescence intensities of M1-ESY assembly (donor and acceptor) and M1 assembly (donor) at $495 \mathrm{~nm}$ when excited at $370 \mathrm{~nm}$, respectively. The energy-transfer efficiency $\left(\Phi_{\mathrm{ET}}\right)$ was calculated as $28.6 \%$ in $\mathrm{H}_{2} \mathrm{O}-\mathrm{CH}_{3} \mathrm{OH}(19: 1$; v/v), measured under the condition of [M1] $=1.0 \times$ $10^{-5} \mathrm{M},[\mathrm{ESY}]=1.0 \times 10^{-7} \mathrm{M}$, and $\lambda_{\mathrm{ex}}=370 \mathrm{~nm}$ (Figure $\left.\mathrm{S} 42 \mathrm{a}\right)$.

For M1-SR101 system, where IDA and ID are the fluorescence intensities of M1-SR101 assembly (donor and acceptor) and M1 assembly (donor) at $495 \mathrm{~nm}$ when excited at $370 \mathrm{~nm}$, respectively. The energy-transfer efficiency $\left(\Phi_{\mathrm{ET}}\right)$ was calculated 
as $24.1 \%$ in $\mathrm{H}_{2} \mathrm{O}-\mathrm{CH}_{3} \mathrm{OH}(19: 1$; v/v), measured under the condition of [M1] $=1.0 \times$ $10^{-5} \mathrm{M},[\mathrm{SR} 101]=1.0 \times 10^{-7} \mathrm{M}$, and $\lambda_{\mathrm{ex}}=370 \mathrm{~nm}($ Figure S42b).

For M1-ESY-SR101 system, where $\mathbf{I}_{\mathbf{D A}}$ and $\mathbf{I}_{\mathbf{D}}$ are the fluorescence intensities of M1-ESY-SR101 assembly (donor and acceptor) and M1-ESY assembly (donor) at $555 \mathrm{~nm}$ when excited at $370 \mathrm{~nm}$, respectively. The energy-transfer efficiency $\left(\Phi_{\mathrm{ET}}\right)$ was calculated as $59.5 \%$ in $\mathrm{H}_{2} \mathrm{O}-\mathrm{CH}_{3} \mathrm{OH}(19: 1$; v/v), measured under the condition of $[\mathrm{M1}]=1.0 \times 10^{-5} \mathrm{M},[\mathrm{ESY}]=1.0 \times 10^{-7} \mathrm{M},[\mathrm{SR} 101]=4.0 \times 10^{-8} \mathrm{M}$, and $\lambda_{\mathrm{ex}}=370 \mathrm{~nm}$ (Figure S42c).

\subsection{Antenna effect (AE) calculation}

The antenna effect (AE) was calculated using equation S2.

Antenna effect $=\left(I_{D A},(\lambda e x=\right.$ donor $)-I_{D},(\lambda e x=$ donor $\left.)\right) / I_{D A},(\lambda e x=$ acceptor $)$

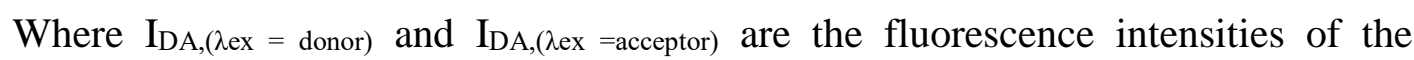
system with excitation of donor and direct excitation of acceptor, respectively. $\mathrm{I}_{\mathrm{D},(\lambda \mathrm{ex}=}$ donor) is the fluorescence intensities of the donor.

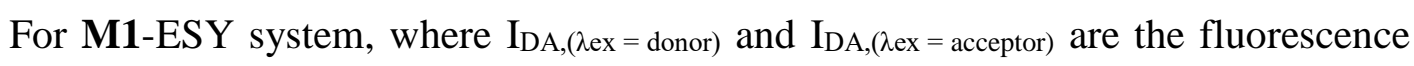
intensities at $555 \mathrm{~nm}$ with the excitation of the donor at $370 \mathrm{~nm}$ and the direct excitation of the acceptor at $500 \mathrm{~nm}$, respectively. $\mathrm{I}_{\mathrm{D},(\lambda \mathrm{ex}=\text { donor) }}$ is the fluorescence intensities at $555 \mathrm{~nm}$ of the M1 assembly, which was normalized with the M1-ESY assembly at $495 \mathrm{~nm}$. The antenna effect value was calculated as 18.3 in $\mathrm{H}_{2} \mathrm{O}-\mathrm{CH}_{3} \mathrm{OH}$ $(19: 1 ; \mathrm{v} / \mathrm{v})$, measured under the condition of $[\mathrm{M1}]=1.0 \times 10^{-5} \mathrm{M},[\mathrm{ESY}]=1.0 \times 10^{-7}$ $\mathrm{M}$, and $\lambda_{\mathrm{ex}}=370 \mathrm{~nm}($ Figure S43).

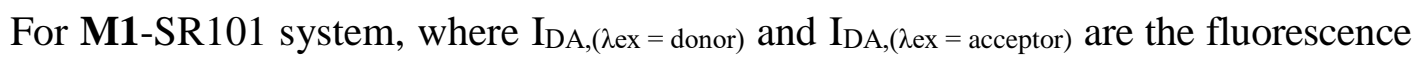
intensities at $607 \mathrm{~nm}$ with the excitation of the donor at $370 \mathrm{~nm}$ and the direct excitation of the acceptor at $580 \mathrm{~nm}$, respectively. $\mathrm{I}_{\mathrm{D},(\lambda \mathrm{ex}=\text { donor) }}$ is the fluorescence intensities at $607 \mathrm{~nm}$ of the M1 assembly, which was normalized with the M1-SR101 assembly at $495 \mathrm{~nm}$. The antenna effect value was calculated as 5.5 in $\mathrm{H}_{2} \mathrm{O}-\mathrm{CH}_{3} \mathrm{OH}$ $(19: 1 ; \mathrm{v} / \mathrm{v})$, measured under the condition of $[\mathrm{M1}]=1.0 \times 10^{-5} \mathrm{M},[\mathrm{SR} 101]=1.0 \times$ $10^{-7} \mathrm{M}$, and $\lambda_{\mathrm{ex}}=370 \mathrm{~nm}($ Figure S43).

For M1-ESY-SR101 system, where $\mathrm{I}_{\mathrm{DA},(\lambda \mathrm{ex}}=$ donor) and $\mathrm{I}_{\mathrm{DA},(\lambda \mathrm{ex}}=$ acceptor $)$ are the fluorescence intensities at $607 \mathrm{~nm}$ with the excitation of the donor at $370 \mathrm{~nm}$ and the 
direct excitation of the acceptor at $580 \mathrm{~nm}$, respectively. $\mathrm{I}_{\mathrm{D},(\lambda e x=\text { donor })}$ is the fluorescence intensities at $607 \mathrm{~nm}$ of the M1-ESY assembly, which was normalized with the M1-ESY-SR101 assembly at $555 \mathrm{~nm}$. The antenna effect value was calculated as 8.9 in $\mathrm{H}_{2} \mathrm{O}-\mathrm{CH}_{3} \mathrm{OH}(19: 1 ; \mathrm{v} / \mathrm{v})$, measured under the condition of [M1] = $1.0 \times 10^{-5} \mathrm{M},[\mathrm{ESY}]=1.0 \times 10^{-7} \mathrm{M},[\mathrm{SR} 101]=4.0 \times 10^{-8} \mathrm{M}$, and $\lambda_{\mathrm{ex}}=370 \mathrm{~nm}$.

\subsection{M1-ESY-SR101 system for the photocatalytic reaction in aqueous} medium.

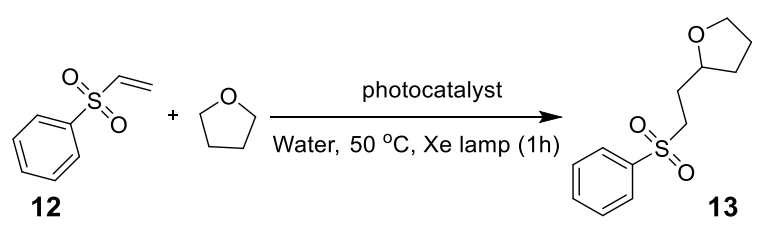

Phenyl vinyl sulfone 12 (0.3 mmol, 1 equiv), tetrahydrofuran (0.5 mL), photocatalyst ( $3 \mu \mathrm{mol}, 1 \mathrm{~mol} \%)$ was dissolved in water $(10 \mathrm{~mL})$ to a $25 \mathrm{~mL}$ quartz Schlenk tube. The mixture was cooled by liquid nitrogen, degassed and purged with nitrogen for three times, and then stirred and irradiated by Xenon lamp at $50{ }^{\circ} \mathrm{C}$. After that, $20 \mathrm{~mL}$ ethyl acetate was added to the resulting mixture. The organic layer was collected and concentrated after washed with saturated $\mathrm{NaHCO}_{3}$ solution and brine. The solvents removed in vacuum give light orange oil. The light orange oil was purified by column chromatography on silica gel to afford $\mathbf{1 3}$ as a white power, yield: $48 \%$. 


\section{Additional tables}

Table S1. Fluorescence lifetimes of M1, M1-ESY and M1-SR101 assembly in $\mathrm{H}_{2} \mathrm{O}-\mathrm{CH}_{3} \mathrm{OH}(19: 1 ; \mathrm{v} / \mathrm{v})$.

\begin{tabular}{|c|c|c|c|c|c|c|}
\hline Sample & $\boldsymbol{\tau}_{1} / \mathbf{n s}$ & $\mathbf{R e l} \%$ & $\boldsymbol{\tau}_{2} / \mathbf{n s}$ & $\mathbf{R e l \%}$ & $\boldsymbol{\tau} / \mathbf{n s}$ & $\boldsymbol{\chi}^{\mathbf{2}}$ \\
\hline M1 $^{\mathrm{a}}$ & 1.36 & 58.40 & 3.59 & 41.60 & 2.29 & 1.225 \\
\hline M1-ESY $^{\mathrm{a}}$ & 0.87 & 55.43 & 2.90 & 44.57 & 1.77 & 1.286 \\
\hline M1-SR101 $^{\mathrm{a}}$ & 1.16 & 59.61 & 3.24 & 40.39 & 2.00 & 1.191 \\
\hline M1-ESY $^{\mathrm{b}}$ & 2.20 & 41.25 & 3.74 & 58.75 & 3.10 & 1.19 \\
\hline M1-ESY-SR101 $^{\mathrm{b}}$ & 1.75 & 36.17 & 3.55 & 63.83 & 2.89 & 1.265 \\
\hline
\end{tabular}

a: monitored at $495 \mathrm{~nm}$ upon excitation at $375 \mathrm{~nm}$; $[$ M1 $]=1.0 \times 10^{-5} \mathrm{M},[$ ESY $]=1.0$ $\times 10^{-7} \mathrm{M},[\mathrm{SR} 101]=1.0 \times 10^{-7} \mathrm{M}$.

b: monitored at $555 \mathrm{~nm}$ upon excitation at $375 \mathrm{~nm}$; [M1] $=1.0 \times 10^{-5} \mathrm{M},[\mathrm{ESY}]=1.0$ $\times 10^{-7} \mathrm{M},[\mathrm{SR} 101]=4.0 \times 10^{-8} \mathrm{M}$.

Table S2. Energy transfer efficiency of M1-ESY assembly in different water fraction.

\begin{tabular}{|c|c|c|c|}
\hline Sample & Concentration & $\begin{array}{c}\text { Water } \\
\text { fraction } \\
\left(f_{\mathrm{w}} \%\right)\end{array}$ & $\begin{array}{c}\text { Energy-transfer } \\
\text { efficiency } \\
\left(\Phi_{\mathrm{ET}}\right)\end{array}$ \\
\hline M1-ESY & $\begin{array}{c}{[\mathrm{M1}]=1.0 \times 10^{-5} \mathrm{M}} \\
{[\mathrm{ESY}]=1.0 \times 10^{-7} \mathrm{M}}\end{array}$ & 30 & $25.9 \%$ \\
\hline M1-ESY & $\begin{array}{c}{[\mathrm{M} 1]=1.0 \times 10^{-5} \mathrm{M}} \\
{[\mathrm{ESY}]=1.0 \times 10^{-7} \mathrm{M}}\end{array}$ & 50 & $48.8 \%$ \\
\hline M1-ESY & $\begin{array}{c}{[\mathrm{M1}]=1.0 \times 10^{-5} \mathrm{M}} \\
{[\mathrm{ESY}]=1.0 \times 10^{-7} \mathrm{M}}\end{array}$ & 70 & $45.5 \%$ \\
\hline M1-ESY & $\begin{array}{c}{[\mathbf{M 1}]=1.0 \times 10^{-5} \mathrm{M}} \\
{[\mathrm{ESY}]=1.0 \times 10^{-7} \mathrm{M}}\end{array}$ & 95 & $28.6 \%$ \\
\hline
\end{tabular}


Table S3. Fluorescence quantum yields of M1 (in the methanol solution), M1 (in the solid state), M1, M1-ESY and M1-ESY-SR101 in $\mathrm{H}_{2} \mathrm{O}-\mathrm{CH}_{3} \mathrm{OH}(19: 1$; v/v).

\begin{tabular}{|c|c|c|}
\hline Sample & Concentration & $\begin{array}{c}\text { Fluorescence quantum } \\
\text { yields }\left(\Phi_{\mathrm{f}(\mathrm{abs})}\right)\end{array}$ \\
\hline M1 in the methanol solution & {$[\mathrm{M1}]=1.0 \times 10^{-5} \mathrm{M}$} & $-{ }^{a}$ \\
\hline M1 in the solid state & & $18.80 \%$ \\
\hline M1 & {$[\mathbf{M 1}]=1.0 \times 10^{-5} \mathrm{M}$} & $15.31 \%$ \\
\hline M1-ESY & $\begin{array}{c}{[\mathrm{M1}]=1.0 \times 10^{-5} \mathrm{M}} \\
{[\mathrm{ESY}]=1.0 \times 10^{-7} \mathrm{M}}\end{array}$ & $19.31 \%$ \\
\hline M1-SR101 & $\begin{array}{c}{[\mathrm{M} 1]=1.0 \times 10^{-5} \mathrm{M}} \\
{[\mathrm{SR} 101]=1.0 \times 10^{-7} \mathrm{M}}\end{array}$ & $27.16 \%$ \\
\hline M1-ESY-SR101 & $\begin{array}{c}{[\mathrm{M} 1]=1.0 \times 10^{-5} \mathrm{M}} \\
{[\mathrm{ESY}]=1.0 \times 10^{-7} \mathrm{M}} \\
{[\mathrm{SR} 101]=4.0 \times 10^{-8} \mathrm{M}}\end{array}$ & $24.06 \%$ \\
\hline
\end{tabular}

${ }^{a} \mathbf{M 1}$ in the methanol solution has very weak fluorescence intensity making it difficult to measure.

Table S4. The energy transfer efficiency in $\mathrm{H}_{2} \mathrm{O}-\mathrm{CH}_{3} \mathrm{OH}(19: 1$; v/v).

\begin{tabular}{|c|c|c|}
\hline Sample & Concentration & $\begin{array}{c}\text { Energy-transfer efficiency } \\
\left(\Phi_{\mathrm{ET}}\right)\end{array}$ \\
\hline $\begin{array}{l}\text { M1-ESY } \\
(100: 1)\end{array}$ & $\begin{array}{c}{[\mathrm{M1}]=1.0 \times 10^{-5} \mathrm{M}} \\
{[\mathrm{ESY}]=1.0 \times 10^{-7} \mathrm{M}}\end{array}$ & $28.6 \%$ \\
\hline $\begin{array}{l}\text { M1-SR101 } \\
\quad(100: 1)\end{array}$ & $\begin{array}{c}{[\mathbf{M 1}]=1.0 \times 10^{-5} \mathrm{M}} \\
{[\mathrm{SR} 101]=1.0 \times 10^{-7} \mathrm{M}}\end{array}$ & $24.1 \%$ \\
\hline $\begin{array}{l}\text { M1-SR101 } \\
\quad(500: 2)\end{array}$ & $\begin{array}{c}{[\mathbf{M 1}]=1.0 \times 10^{-5} \mathrm{M}} \\
{[\mathrm{SR} 101]=4.0 \times 10^{-8} \mathrm{M}}\end{array}$ & $6.8 \%$ \\
\hline $\begin{array}{l}\text { M1-ESY-SR101 } \\
\quad(500: 5: 2)\end{array}$ & $\begin{array}{c}{[\mathrm{M1}]=1.0 \times 10^{-5} \mathrm{M}} \\
{[\mathrm{ESY}]=1.0 \times 10^{-7} \mathrm{M}} \\
{[\mathrm{SR} 101]=4.0 \times 10^{-8} \mathrm{M}}\end{array}$ & $\begin{array}{c}59.5 \% \\
\text { (the second-step) }\end{array}$ \\
\hline
\end{tabular}


Table S5. Antenna effect.

\begin{tabular}{ccc}
\hline Sample & Concentration & Antenna effect (AE) \\
M1-ESY & {$[$ M1 $]=1.0 \times 10^{-5} \mathrm{M}$} & \\
$(100: 1)$ & {$[\mathrm{ESY}]=1.0 \times 10^{-7} \mathrm{M}$} & 18.3 \\
& {$[\mathrm{M} 1]=1.0 \times 10^{-5} \mathrm{M}$} & \\
M1-SR101 & {$[\mathrm{SR} 101]=1.0 \times 10^{-7} \mathrm{M}$} & 5.5 \\
$(100: 1)$ & {$[$ M1 $]=1.0 \times 10^{-5} \mathrm{M}$} & \\
& {$[\mathrm{SR} 101]=4.0 \times 10^{-8} \mathrm{M}$} & 7.8 \\
M1-SR101 & {$[$ M1 $]=1.0 \times 10^{-5} \mathrm{M}$} & \\
$(500: 2)$ & {$[\mathrm{ESY}]=1.0 \times 10^{-7} \mathrm{M}$} & (the second step) \\
& {$[\mathrm{SR} 101]=4.0 \times 10^{-8} \mathrm{M}$} & \\
M1-ESY-SR101 & &
\end{tabular}




\section{Additional Spectra and images}
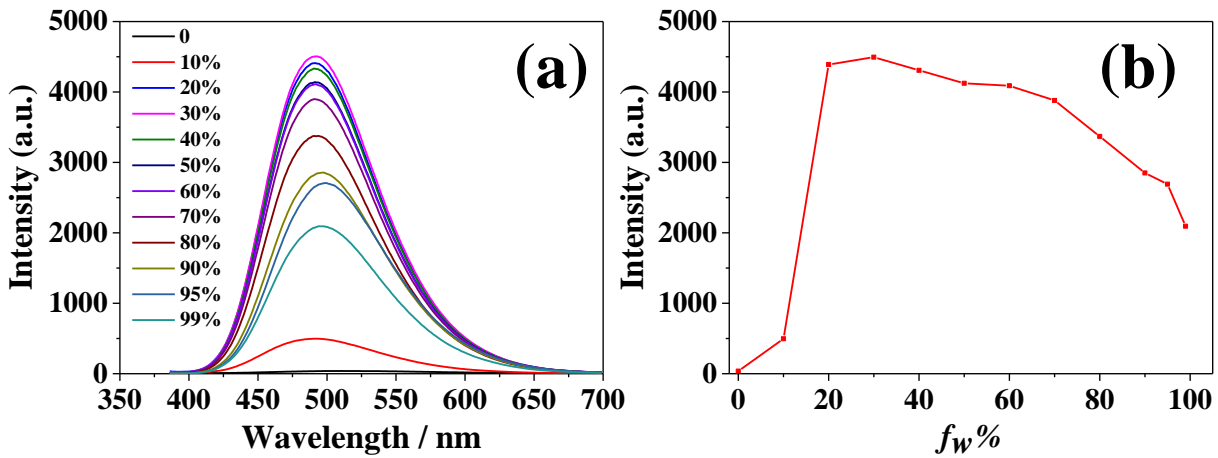

Figure S28. (a) Fluorescence spectra of $\mathbf{M 1}\left(5.0 \times 10^{-6} \mathrm{M}\right)$ in $\mathrm{CH}_{3} \mathrm{OH} / \mathrm{H}_{2} \mathrm{O}$ mixtures with different water volume fractions $\left(f_{\mathrm{w}}, \mathrm{vol} \%\right)\left(\lambda_{\mathrm{ex}}=370 \mathrm{~nm}\right)$. (b) Fluorescence intensity of M1 at $495 \mathrm{~nm}$ with various fractions of water from 0 to $99 \%$.

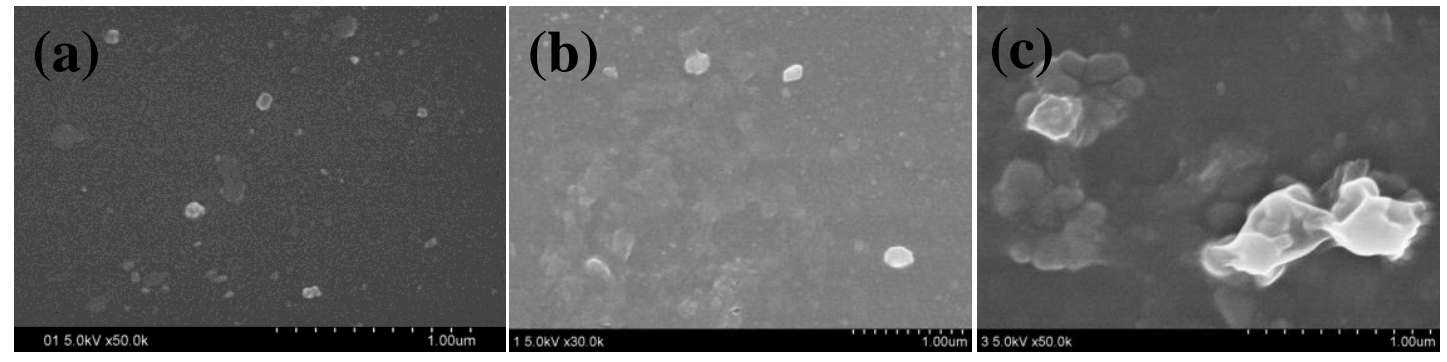

Figure S29. SEM images of M1 assembly (a), M1-ESY assembly (b), and M1-ESY-SR101 assembly (c) in $\mathrm{H}_{2} \mathrm{O}-\mathrm{CH}_{3} \mathrm{OH}(19: 1 ; \mathrm{v} / \mathrm{v})$. [M1] $=1.0 \times 10^{-6} \mathrm{M}$, [ESY] $=1.0 \times 10^{-8} \mathrm{M}$, and $[\mathrm{SR} 101]=4.0 \times 10^{-9} \mathrm{M}$. 

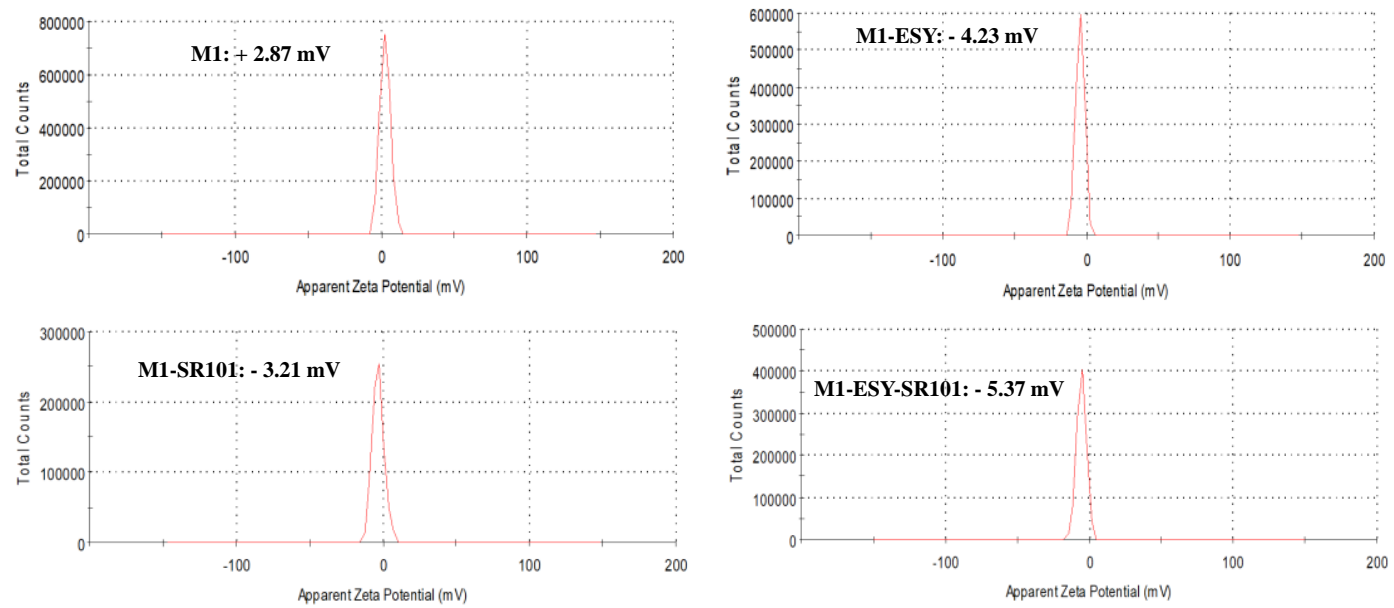

Figure S30. Zeta potentials of M1 assemblies, M1-ESY (100:1) assemblies, M1-SR101 (100:1) assemblies and M1-ESY-SR101 (500:5:2) assemblies in $\mathrm{H}_{2} \mathrm{O}-\mathrm{CH}_{3} \mathrm{OH}(19: 1 ; \mathrm{v} / \mathrm{v})$.

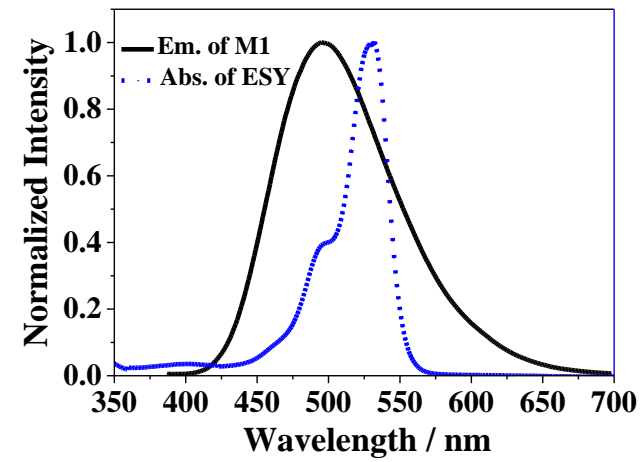

Figure S31. Normalized absorption spectrum of ESY and emission spectrum of M1.

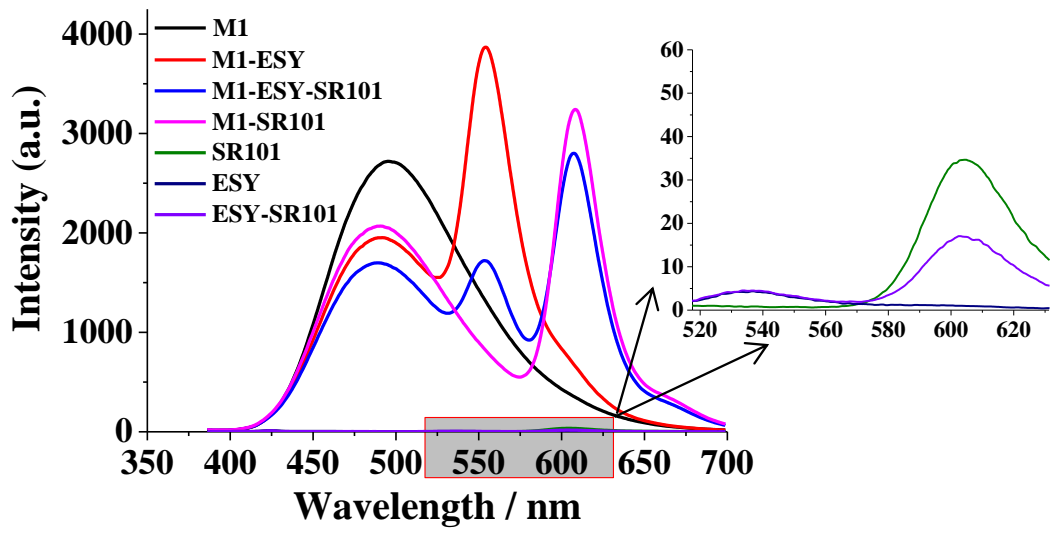

Figure S32. Fluorescence spectra of M1, M1-ESY, M1-SR101, M1-ESY-SR101, SR101, ESY and ESY-SR101 $\left(\lambda_{\text {ex }}=370 \mathrm{~nm}\right)$ in $\mathrm{H}_{2} \mathrm{O}-\mathrm{CH}_{3} \mathrm{OH}(19: 1 ; \mathrm{v} / \mathrm{v})$. 


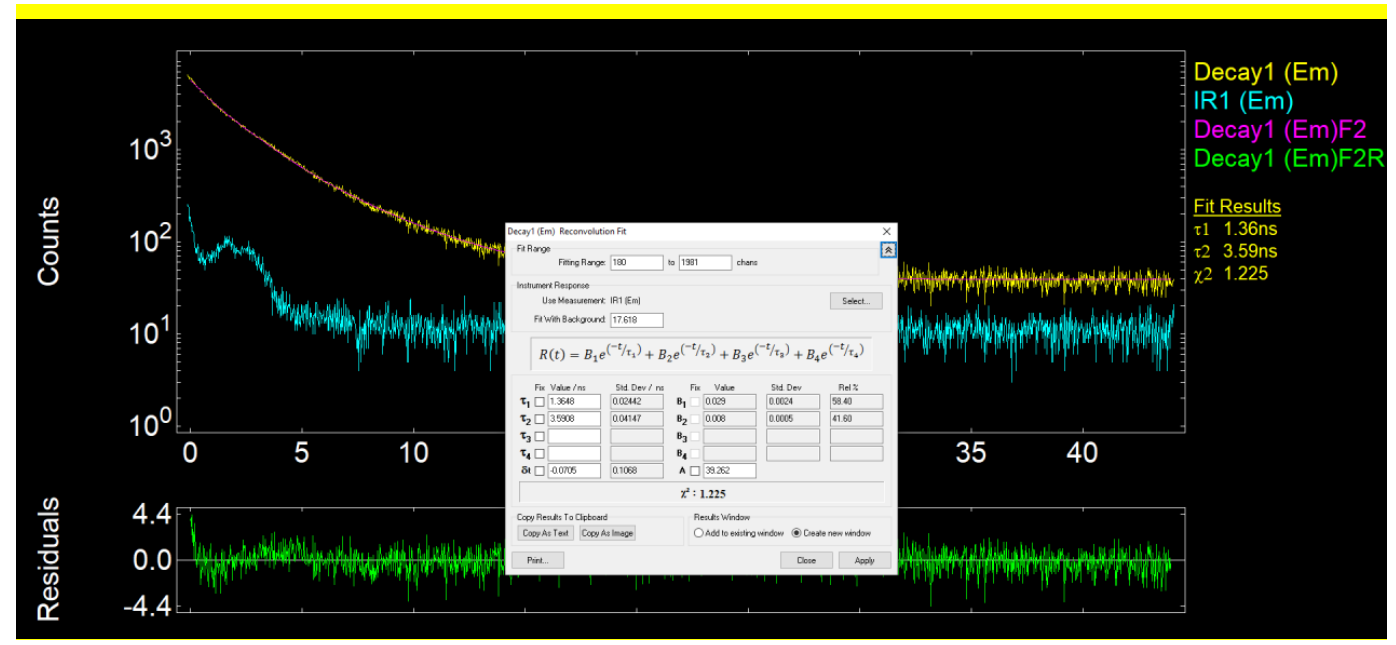

Figure S33. Fluorescence decay profile of M1 assembly monitored at $495 \mathrm{~nm}$ upon excitation at $375 \mathrm{~nm}$.

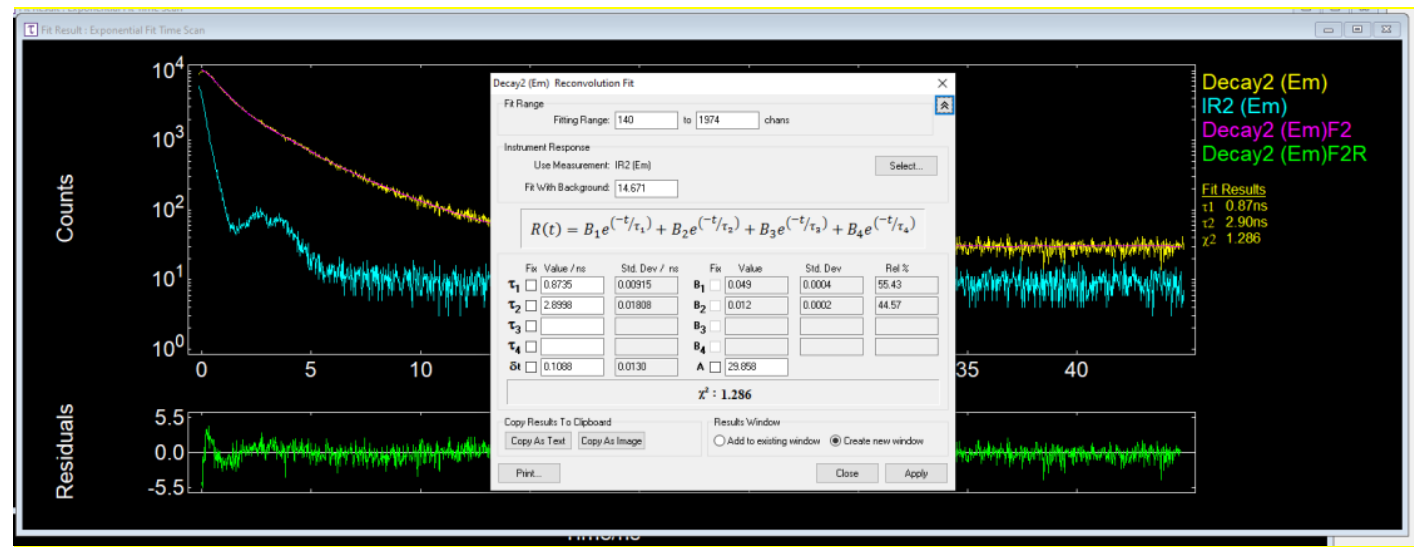

Figure S34. Fluorescence decay profile of M1-ESY (100:1) assembly monitored at $495 \mathrm{~nm}$ upon excitation at $375 \mathrm{~nm}$.

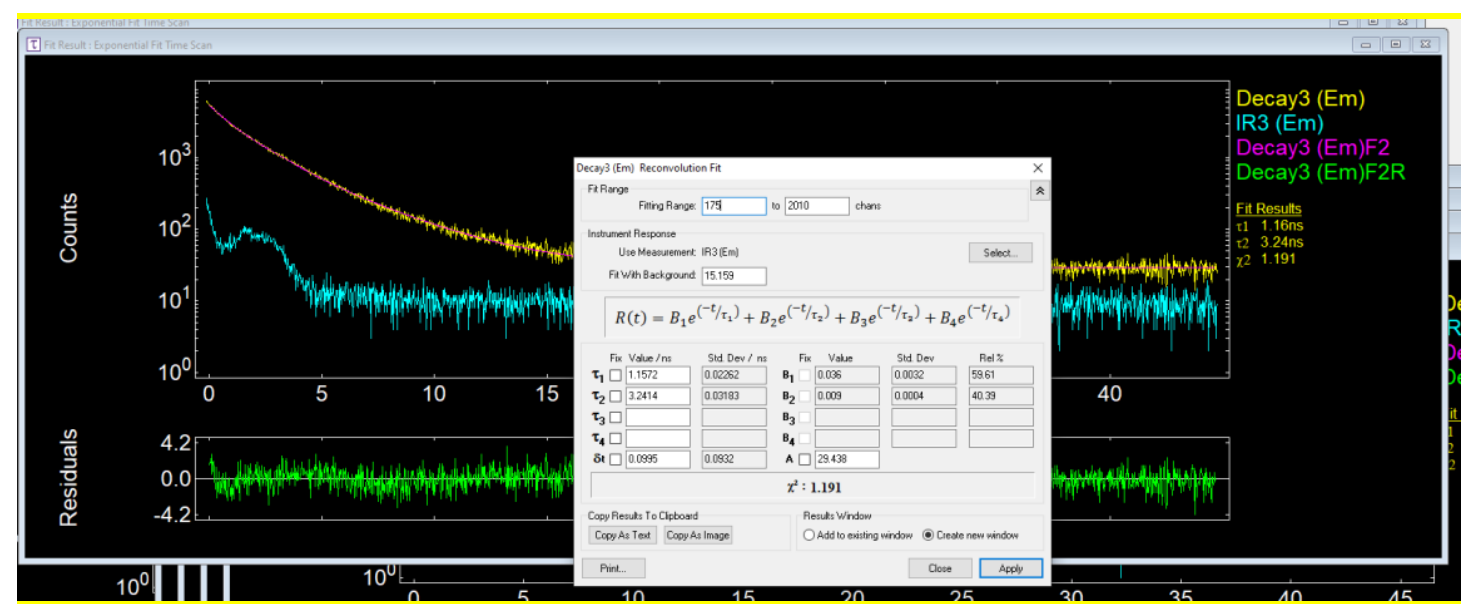

Figure S35. Fluorescence decay profile of M1-SR101 (100:1) assembly monitored at $495 \mathrm{~nm}$ upon excitation at $375 \mathrm{~nm}$. 

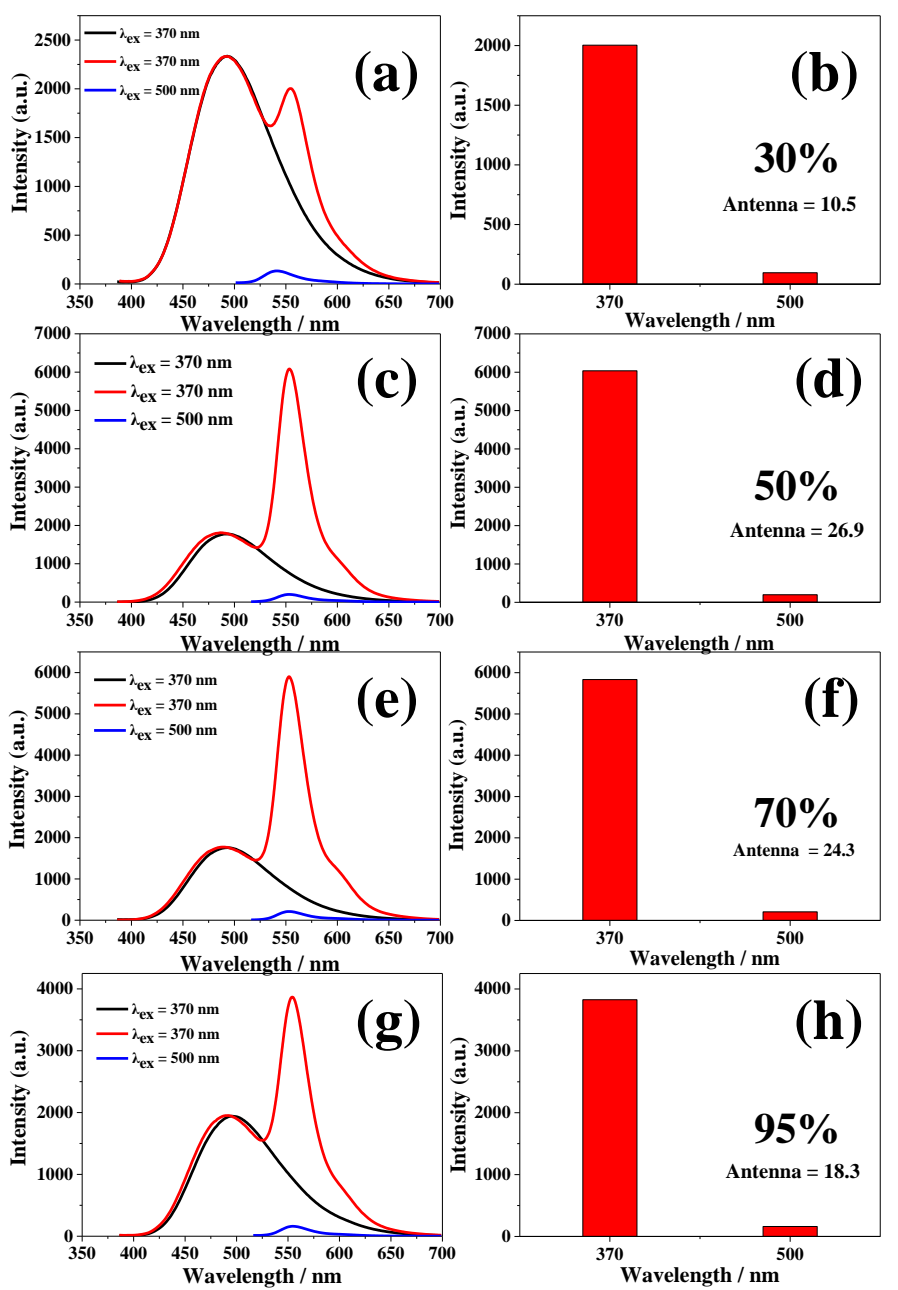

Figure S33. a, c, e), g) Fluorescence spectra of M1-ESY $\left([\mathbf{M 1}]=1.0 \times 10^{-5} \mathrm{M}\right.$, [ESY] $=1.0 \times 10^{-7} \mathrm{M}$ ) in different water fraction, red trace (donor emission, $\lambda_{\mathrm{ex}}=370 \mathrm{~nm}$ ), blue trace (acceptor emission, $\lambda_{\mathrm{ex}}=500 \mathrm{~nm}$ ). The black trace represents the fluorescence spectrum $\left(\lambda_{\mathrm{ex}}=370 \mathrm{~nm}\right)$ of $\mathbf{M 1}\left([\mathbf{M 1}]=1.0 \times 10^{-5} \mathrm{M}\right)$, which was normalized according to the fluorescence intensity at $495 \mathrm{~nm}$ of the red trace; b, d, f), h) The histogram of the ESY emission intensities at $555 \mathrm{~nm}\left([\mathbf{M 1}]=1.0 \times 10^{-5} \mathrm{M}\right.$, $\left.[\mathrm{ESY}]=1.0 \times 10^{-7} \mathrm{M}\right)$ on excitation of the donor $\left(\lambda_{\mathrm{ex}}=370 \mathrm{~nm}\right)$ and acceptor $\left(\lambda_{\mathrm{ex}}=\right.$ $500 \mathrm{~nm})$.

The efficiency of energy transfer in the $\mathrm{H}_{2} \mathrm{O}-\mathrm{CH}_{3} \mathrm{OH}$ mixture with different water contents $\left(f_{\mathrm{w}}\right)$ was investigated (Figure S36 and Table S2). When $f_{\mathrm{w}}<30 \%$, the efficiency of energy transfer was relatively low. The energy transfer efficiency 
reached a maximum at $f_{\mathrm{w}}=50 \%$, and decreased moderately upon exceeding this point. To better mimic natural LHS, $f_{\mathrm{w}}=95 \%$ was chosen.

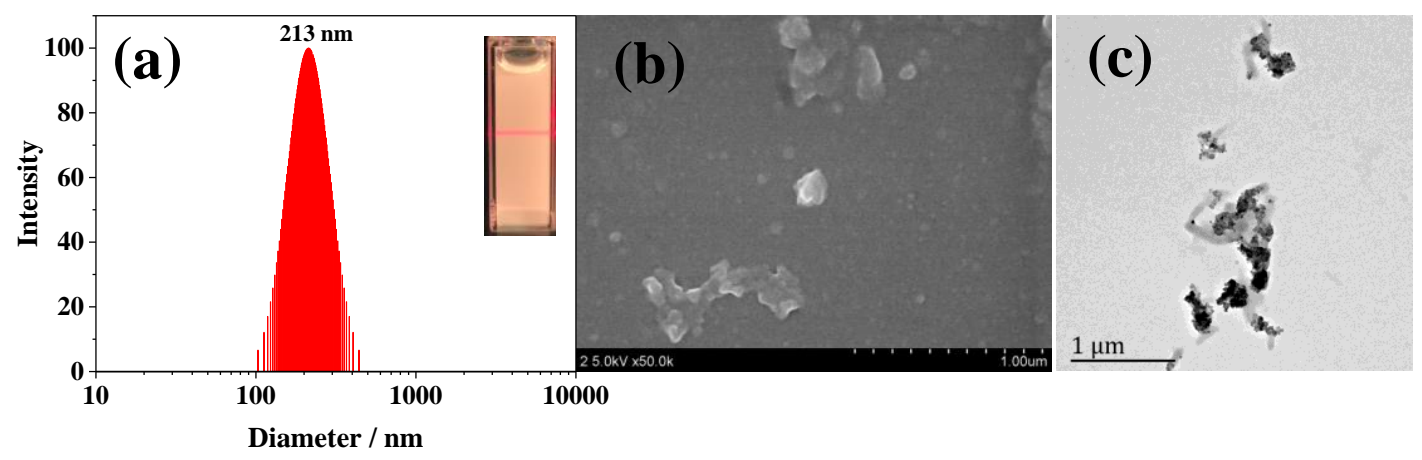

Figure S34. (a) DLS profiles of M1-SR101 assembly. (b) SEM images of M1-SR101 assembly. (c) TEM images of M1-SR101 assembly in $\mathrm{H}_{2} \mathrm{O}-\mathrm{CH}_{3} \mathrm{OH}(19: 1$; v/v). Inset: the Tyndall effect of M1-SR101 system. $[$ M1 $]=1.0 \times 10^{-6} \mathrm{M},[\mathrm{SR} 101]=1.0 \times 10^{-8} \mathrm{M}$. 


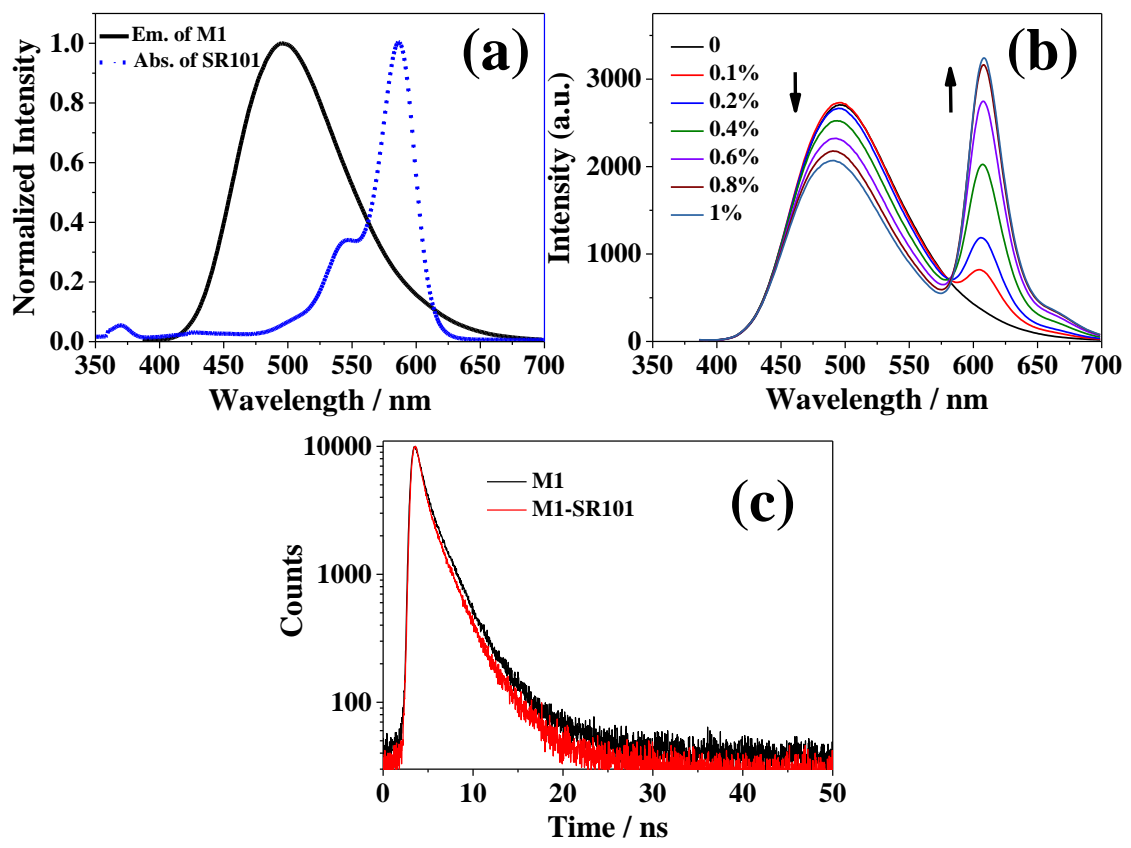

Figure S35. (a) Normalized absorption spectrum of SR101 and emission spectrum of M1. (b) Fluorescence spectra of M1 with different concentrations of SR101 ( $\lambda_{\mathrm{ex}}=370$ $\mathrm{nm})$ in $\mathrm{H}_{2} \mathrm{O}-\mathrm{CH}_{3} \mathrm{OH}(19: 1 ; \mathrm{v} / \mathrm{v})$. (c) Fluorescence decay profiles of $\mathbf{M 1}$ nanoparticles (black line) and M1-SR101 nanoparticles (M1:SR101 = 100:1) in $\mathrm{H}_{2} \mathrm{O}-\mathrm{CH}_{3} \mathrm{OH}$ (19:1; $\mathrm{v} / \mathrm{v})$.

To extend the range of emission wavelengths, SR101 was also loaded as acceptor into the M1 assembly (Figures S37, S38). In M1-SR101 system, the energy transfer efficiency was calculated to be $24.1 \%$, and the antenna effect was calculated to be 5.5 at the donor/acceptor ratio of 100:1 (Tables S4, S5), lower than that of M1-ESY system, owing to the less overlap between the absorption spectrum of SR101 and the emission spectrum of M1 (Figure S38a). 


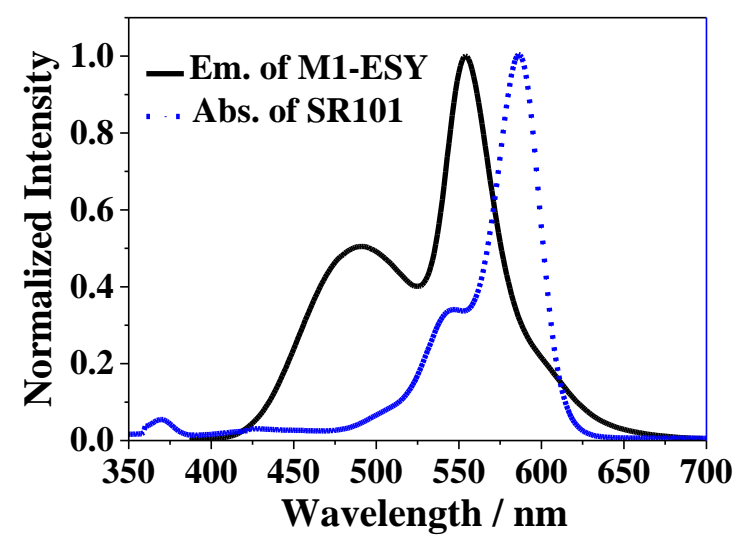

Figure 36. Normalized absorption spectrum of SR101 and emission spectrum of M1-ESY assembly.

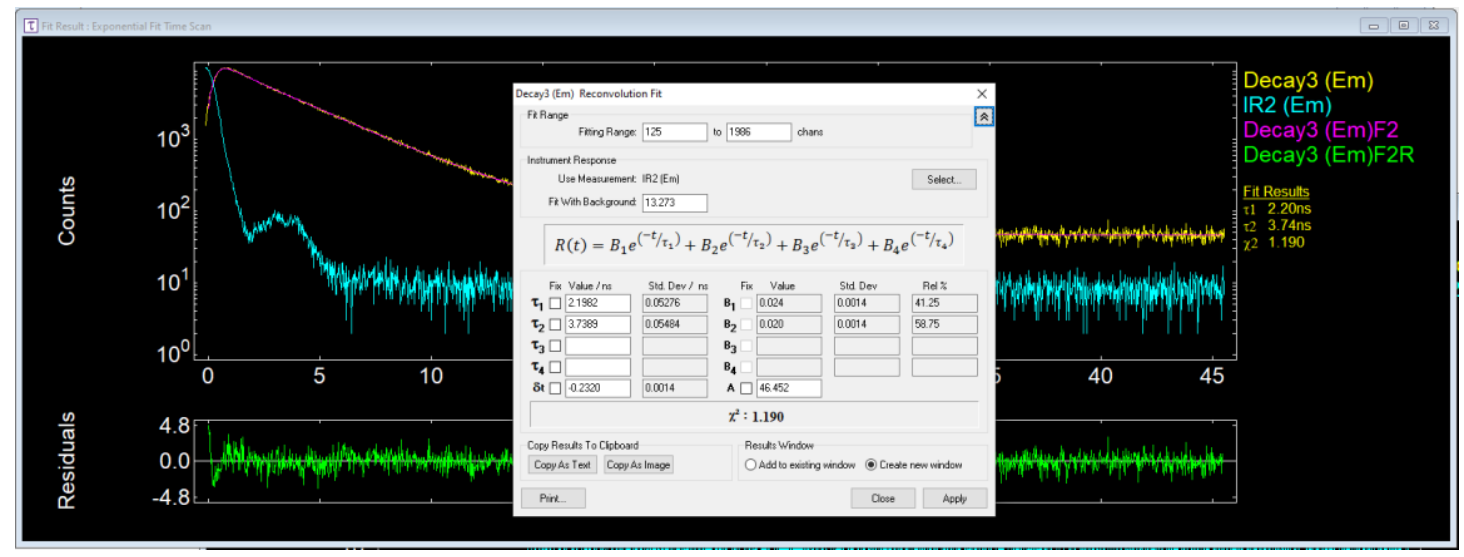

Figure S40. Fluorescence decay profile of M1-ESY (100:1) assembly monitored at $555 \mathrm{~nm}$ upon excitation at $375 \mathrm{~nm}$.

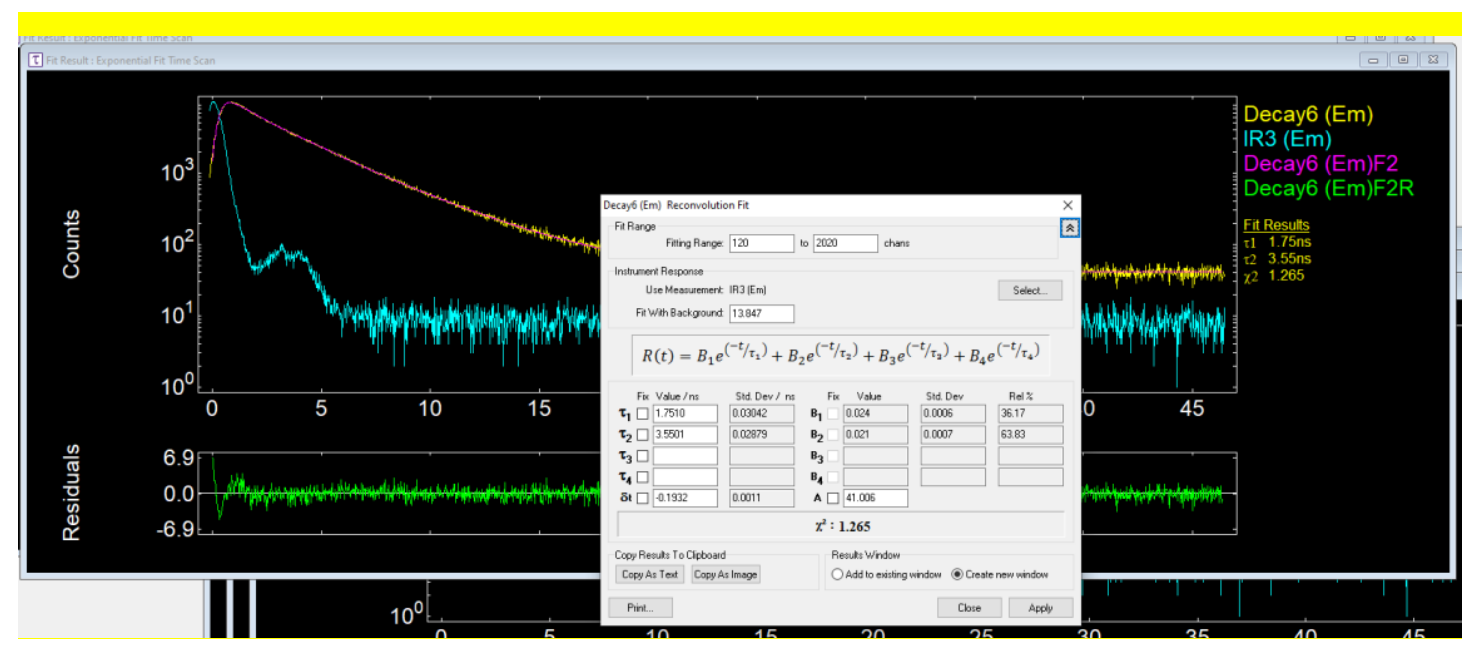

Figure S41. Fluorescence decay profile of M1-ESY-SR101 (500:5:2) assembly monitored at $555 \mathrm{~nm}$ upon excitation at $375 \mathrm{~nm}$. 


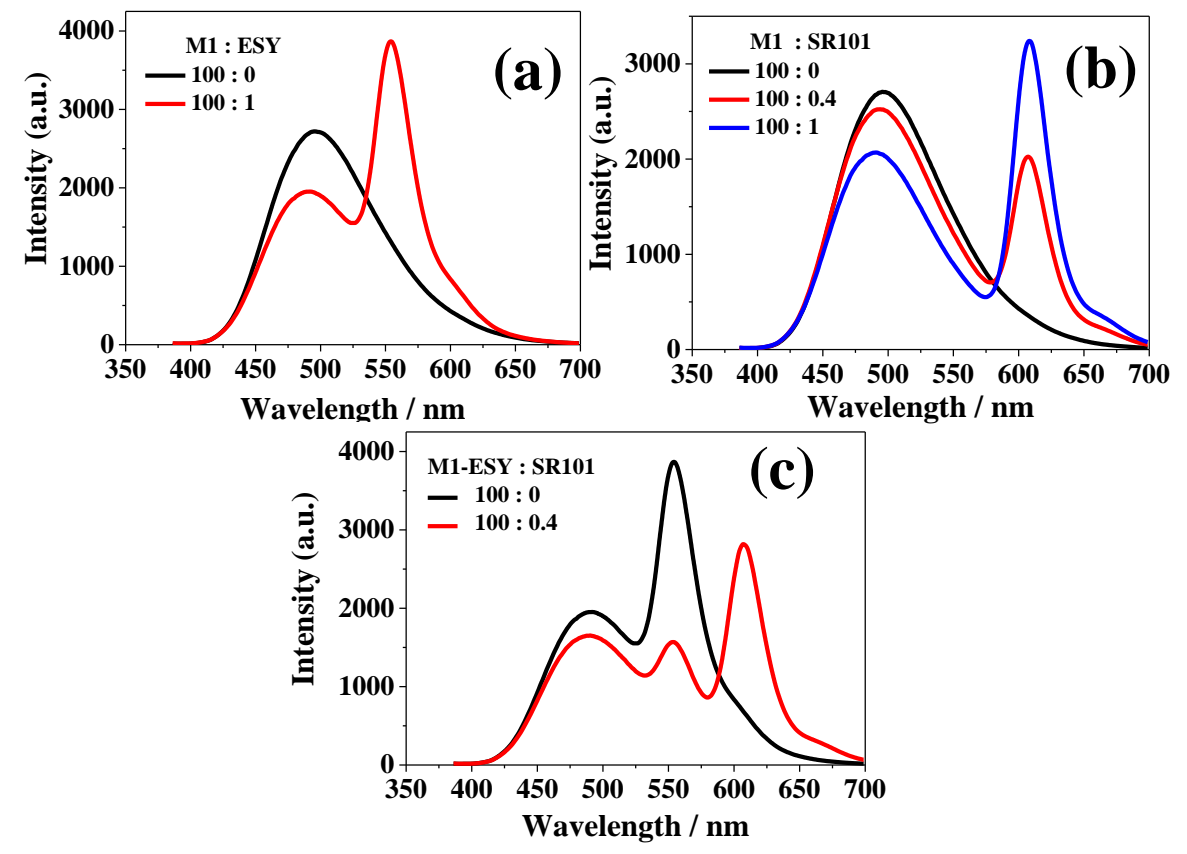

Figure S42. Fluorescence spectra of a) M1 and M1-ESY assembly, b) M1 and M1-SR101 assembly, and c) M1-ESY and M1-ESY-SR101 assembly. [M1] $=1.0 \times$ $10^{-5} \mathrm{M}$. 

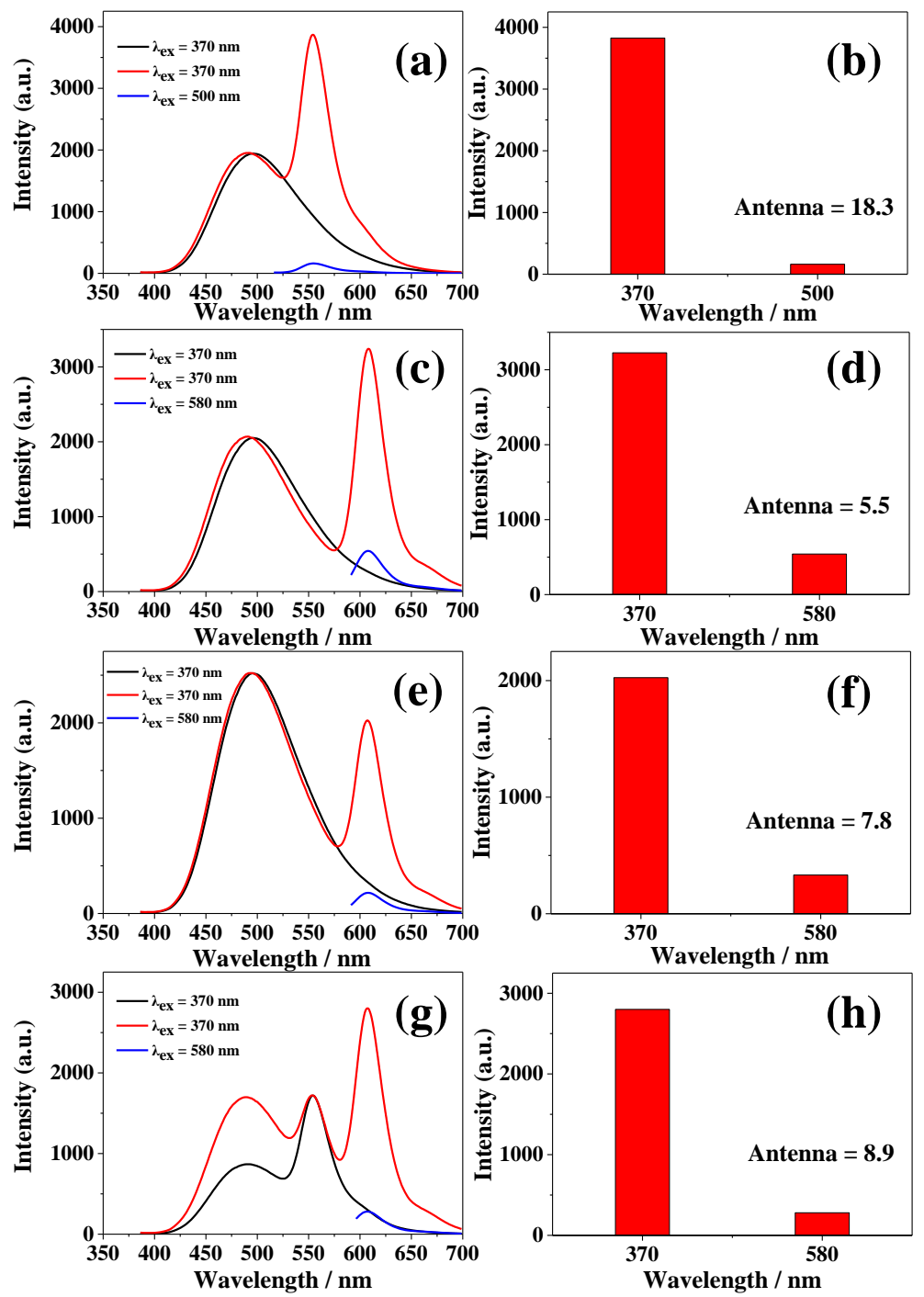

Figure S43. (a) Fluorescence spectra of M1-ESY ([M1] $=1.0 \times 10^{-5} \mathrm{M}$, [ESY] $=$ $1.0 \times 10^{-7} \mathrm{M}$ ), red trace (donor emission, $\lambda_{\mathrm{ex}}=370 \mathrm{~nm}$ ), blue trace (acceptor emission, $\left.\lambda_{\mathrm{ex}}=500 \mathrm{~nm}\right)$. The black trace represents the fluorescence spectrum $\left(\lambda_{\mathrm{ex}}=370 \mathrm{~nm}\right)$ of M1 $\left([\mathbf{M 1}]=1.0 \times 10^{-5} \mathrm{M}\right)$, which was normalized according to the fluorescence intensity at $495 \mathrm{~nm}$ of the red trace; (b) The histogram of the eosin $\mathrm{Y}$ emission intensities at $555 \mathrm{~nm}\left([\mathrm{M1}]=1.0 \times 10^{-5} \mathrm{M},[\mathrm{ESY}]=1.0 \times 10^{-7} \mathrm{M}\right)$ on excitation of the donor $\left(\lambda_{\mathrm{ex}}=370 \mathrm{~nm}\right)$ and acceptor $\left(\lambda_{\mathrm{ex}}=500 \mathrm{~nm}\right)$. (c) Fluorescence spectra of M1-SR101 $\left([\mathrm{M1}]=1.0 \times 10^{-5} \mathrm{M},[\mathrm{SR} 101]=1.0 \times 10^{-7} \mathrm{M}\right)$, red trace $($ donor emission, $\lambda_{\mathrm{ex}}=370 \mathrm{~nm}$ ), blue trace (acceptor emission, $\lambda_{\mathrm{ex}}=580 \mathrm{~nm}$ ). The black trace represents the fluorescence spectrum $\left(\lambda_{\mathrm{ex}}=370 \mathrm{~nm}\right)$ of $\mathbf{M 1}\left([\mathbf{M 1}]=1.0 \times 10^{-5} \mathrm{M}\right)$, which was normalized according to the fluorescence intensity at $495 \mathrm{~nm}$ of the red trace; (d) The histogram of the SR101 emission intensities at $607 \mathrm{~nm}([\mathbf{M 1}]=$ 
$\left.1.0 \times 10^{-5} \mathrm{M},[\mathrm{SR} 101]=1.0 \times 10^{-7} \mathrm{M}\right)$ on excitation of the donor $\left(\lambda_{\mathrm{ex}}=370 \mathrm{~nm}\right)$ and acceptor $\left(\lambda_{\mathrm{ex}}=580 \mathrm{~nm}\right)$. (e) Fluorescence spectra of M1-SR101 $\left([\mathrm{M1}]=1.0 \times 10^{-5} \mathrm{M}\right.$, $[\mathrm{SR} 101]=4.0 \times 10^{-8} \mathrm{M}$ ), red trace (donor emission, $\lambda_{\mathrm{ex}}=370 \mathrm{~nm}$ ), blue trace (acceptor emission, $\left.\lambda_{\mathrm{ex}}=580 \mathrm{~nm}\right)$. The black trace represents the fluorescence spectrum $\left(\lambda_{\mathrm{ex}}=\right.$ $370 \mathrm{~nm})$ of M1 $\left([\mathbf{M 1}]=1.0 \times 10^{-5} \mathrm{M}\right)$, which was normalized according to the fluorescence intensity at $495 \mathrm{~nm}$ of the red trace; (f) The histogram of the SR101 emission intensities at $607 \mathrm{~nm}\left([\mathrm{M1}]=1.0 \times 10^{-5} \mathrm{M},[\mathrm{SR} 101]=4.0 \times 10^{-8} \mathrm{M}\right)$ on excitation of the donor $\left(\lambda_{\mathrm{ex}}=370 \mathrm{~nm}\right)$ and acceptor $\left(\lambda_{\mathrm{ex}}=580 \mathrm{~nm}\right)$. $(\mathrm{g})$ Fluorescence spectra of M1-ESY-SR101 $\left([\mathrm{M1}]=1.0 \times 10^{-5} \mathrm{M},[\mathrm{ESY}]=1.0 \times 10^{-7} \mathrm{M},[\mathrm{SR} 101]=\right.$ $4.0 \times 10^{-8} \mathrm{M}$ ), red trace (donor emission, $\lambda_{\mathrm{ex}}=370 \mathrm{~nm}$ ), blue trace (acceptor emission, $\left.\lambda_{\mathrm{ex}}=580 \mathrm{~nm}\right)$. The black trace represents the fluorescence spectrum $\left(\lambda_{\mathrm{ex}}=370 \mathrm{~nm}\right)$ of M1-ESY $\left([\mathbf{M 1}]=1.0 \times 10^{-5} \mathrm{M},[\mathrm{ESY}]=1.0 \times 10^{-7} \mathrm{M}\right)$, which was normalized according to the fluorescence intensity at $555 \mathrm{~nm}$ of the red trace; (h) The histogram of the SR101 emission intensities at $607 \mathrm{~nm}\left([\mathrm{M1}]=1.0 \times 10^{-5} \mathrm{M},[\mathrm{ESY}]=1.0 \times 10^{-7} \mathrm{M}\right.$, $\left.[\mathrm{SR} 101]=4 \times 10^{-8} \mathrm{M}\right)$ on excitation of the donor $\left(\lambda_{\mathrm{ex}}=370 \mathrm{~nm}\right)$ and acceptor $\left(\lambda_{\mathrm{ex}}=\right.$ $580 \mathrm{~nm})$.
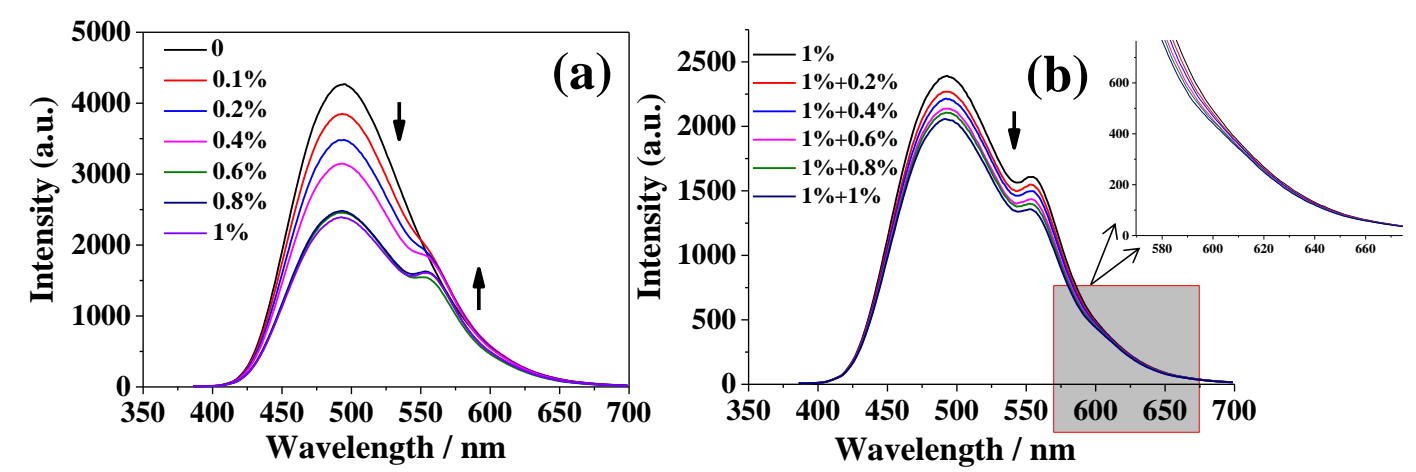

Figure S44. (a) Fluorescence spectra of M2 with different amounts of ESY. (b) Fluorescence spectra of M2-ESY with different amounts of SR101. ([M2] $=1.0 \times 10^{-5}$ $\left.\mathrm{M}, \lambda_{\mathrm{ex}}=360 \mathrm{~nm}\right)$ in $\mathrm{H}_{2} \mathrm{O}-\mathrm{THF}(19: 1 ; \mathrm{v} / \mathrm{v})$. 


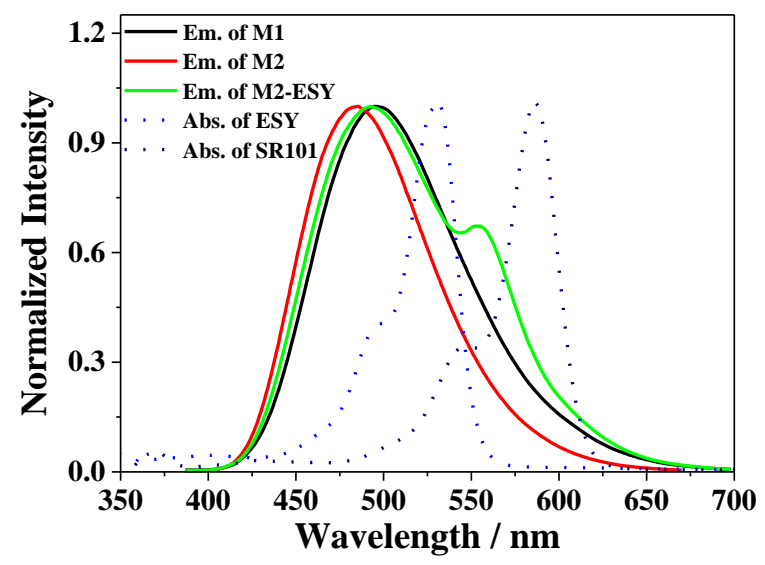

Figure S37. Normalized absorption spectra of ESY and SR101 and emission spectra of M1, M2 and M2-ESY.

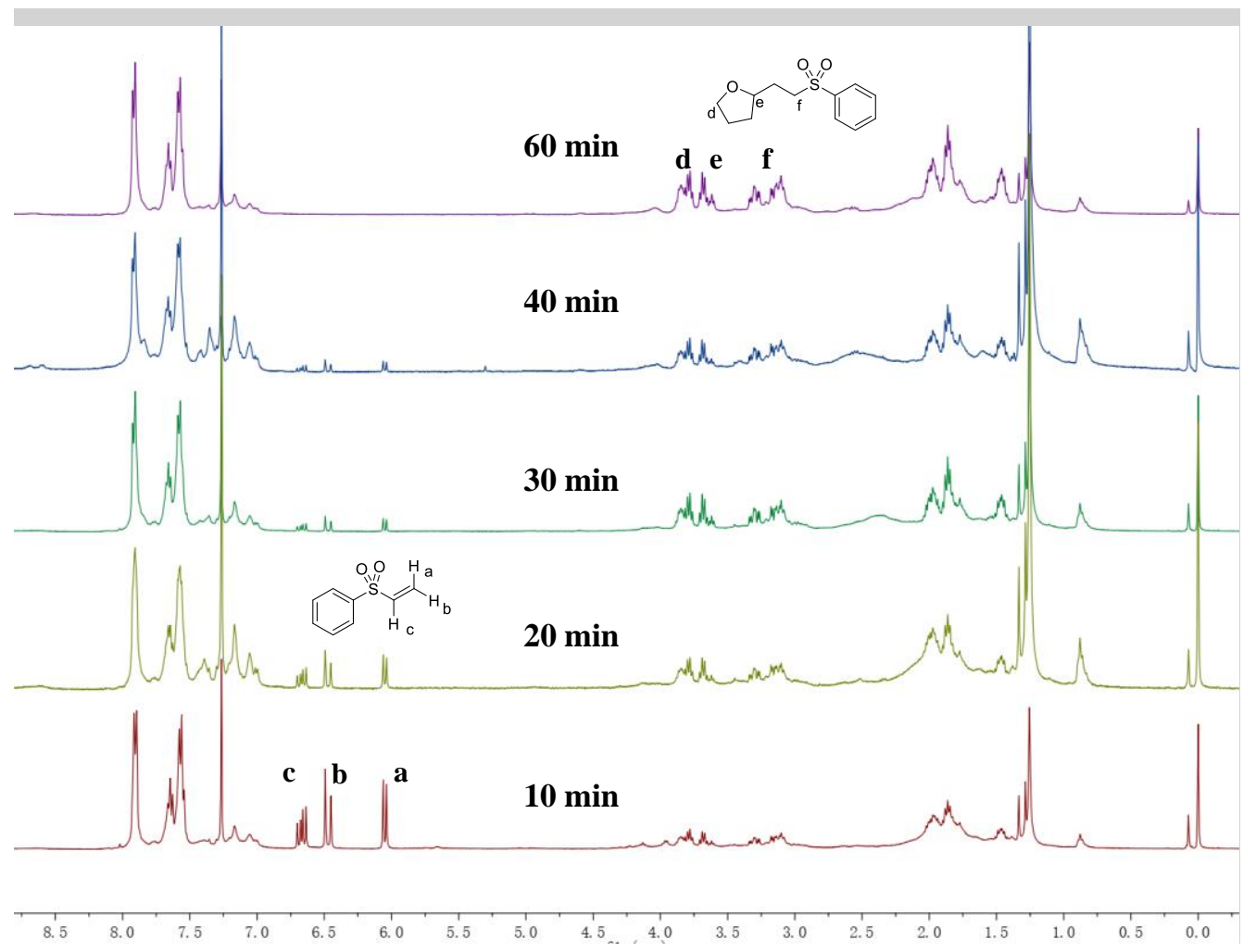

Figure S46. ${ }^{1} \mathrm{H}$ NMR spectra $\left(400 \mathrm{MHz}, \mathrm{CDCl}_{3}, 298 \mathrm{~K}\right)$ of the reaction of phenyl vinyl sulfone and tetrahydrofuran using M1-ESY-SR101 as photocatalyst at 10-60 $\min$. 


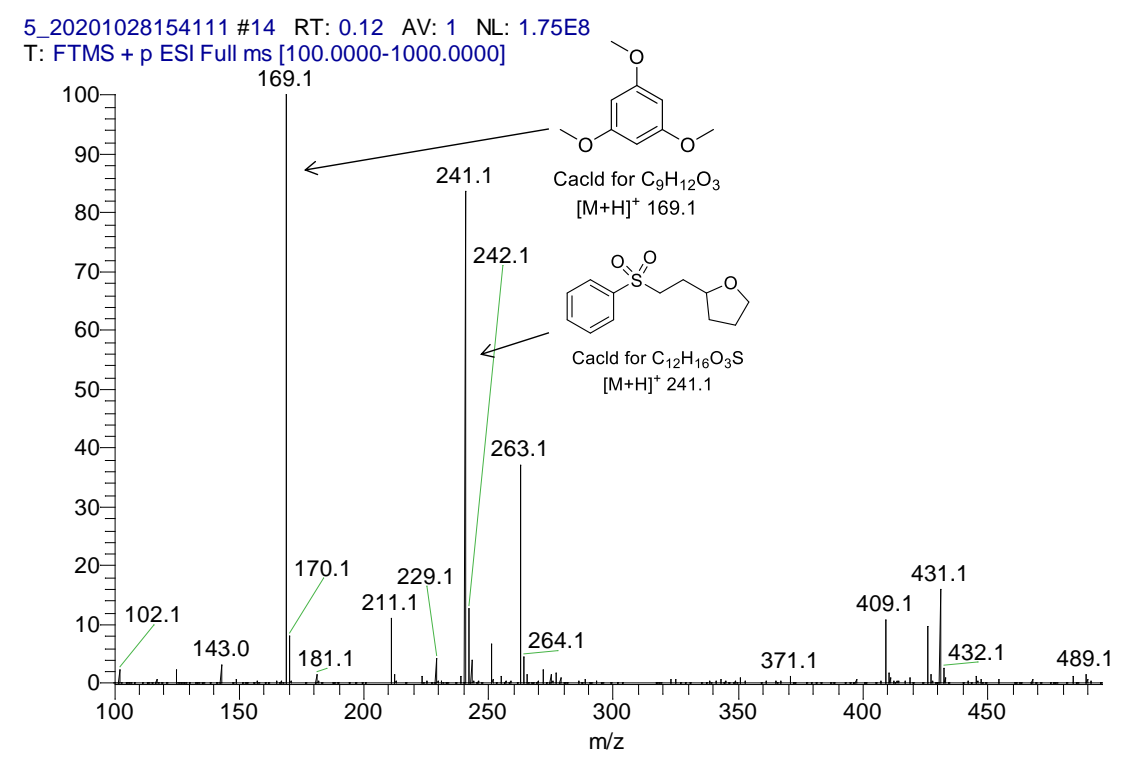

Figure S47. ESI spectrum of the reaction using M1-ESY-SR101 as photocatalyst at 1 $\mathrm{h}$ by using $1,3,5$-trimethoxybenzene $(15 \mathrm{mM})$ as an internal standard.

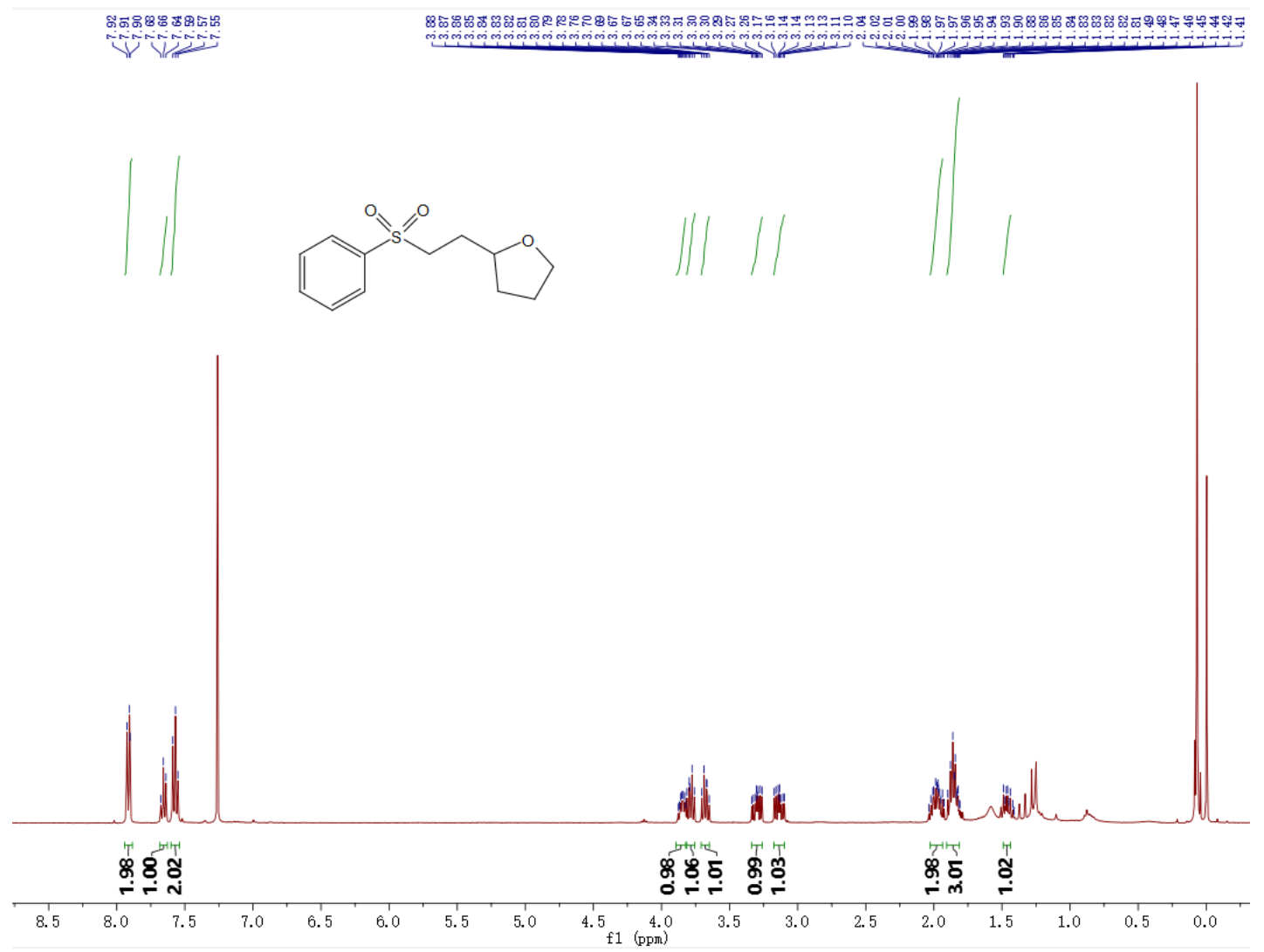

Figure S48. ${ }^{1} \mathrm{H}$ NMR spectrum $\left(400 \mathrm{MHz}, \mathrm{CDCl}_{3}, 298 \mathrm{~K}\right)$ of $\mathbf{1 3}$. 


\section{References}

[1] Wang, E.; He, Z.; Zhao, E.; Meng, L.; Schütt, C.; Lam, J. W. Y.; Sung H. H. Y.;

Williams, I. D.; Huang, X.; Herges, R.; Tang B. Aggregation-Induced-Emission-Active Macrocycle Exhibiting Analogous Triply and Singly Twisted Möbius Topologies. Chem. Eur. J. 2015, 21, 11707-11711.

[2] Stang, P. J.; Cao, D. H.; Saito, S. Arif, A. M. Self-Assembly of Cationic, Tetranuclear, Pt(II) and Pd(II) Macrocyclic Squares. X-ray Crystal Structure of $\left[\mathrm{Pt}^{2+}(\mathrm{dppp})(4,4 \text { '-bipyridyl) })_{2} \mathrm{OSSO}_{2} \mathrm{CF}_{3}\right]_{4}$. J. Am. Chem. Soc. 1995, 117, 6273-6283.

[3] Yang L.; Xu X.; Yu W.; Li X.; Zhang D. AIE-Active Shape-Persistent Macrocycles for the Efficient Discrimination of Toluene. Dyes and Pigments. 2020, $181,108612$. 